ORNL/TM-2019/1131

CRADA/NFE-16-06256

\title{
COMPRESSOR-LESS HYDROGEN REFUELING STATION USING THERMAL COMPRESSION
}

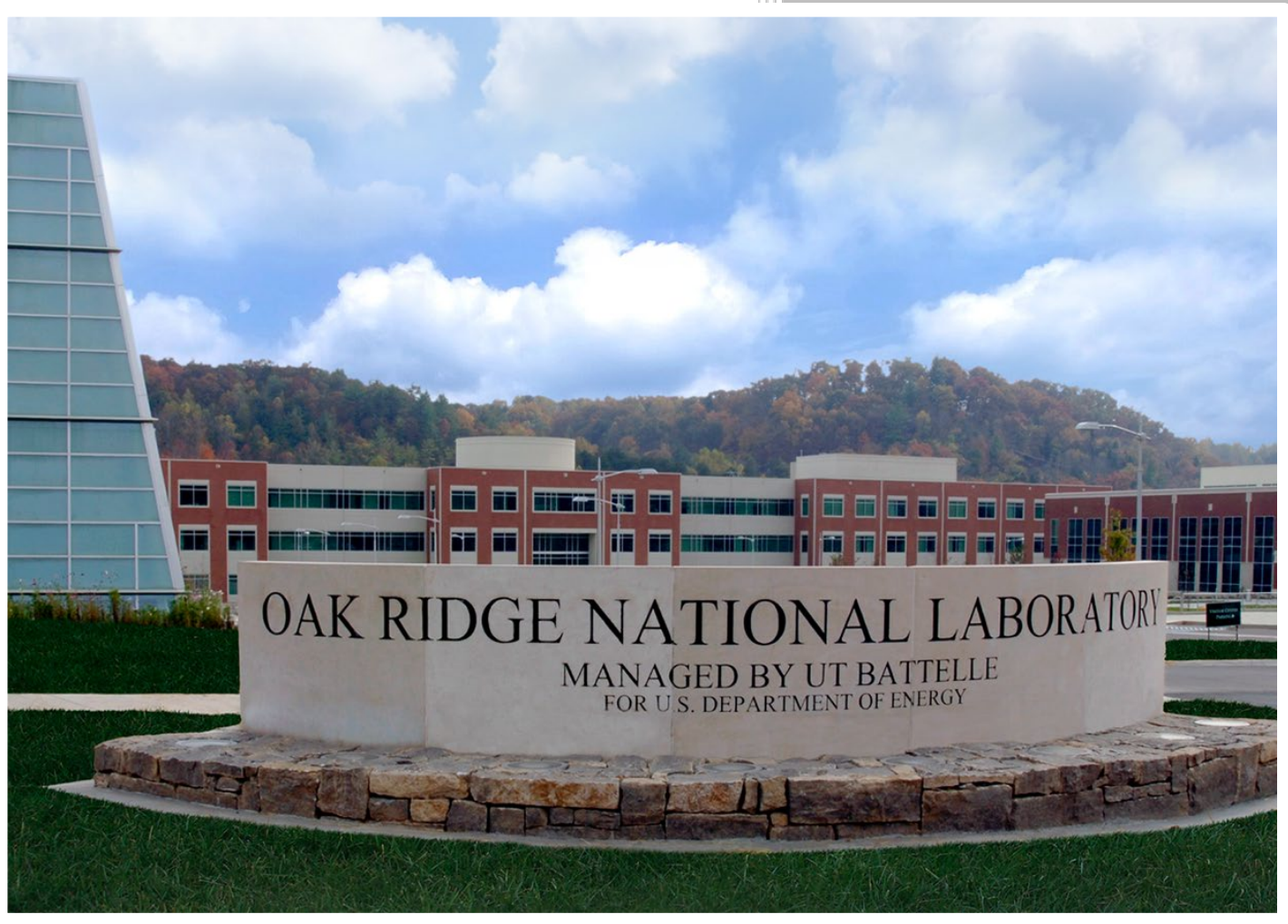

\begin{tabular}{|c|}
\hline $\begin{array}{c}\text { CRADA FINAL REPORT } \\
\text { NFE-16-06256 }\end{array}$ \\
\hline $\begin{array}{c}\text { Approved for public release. } \\
\text { Distribution is unlimited. }\end{array}$ \\
\hline
\end{tabular}

OAK RIDGE NATIONAL LABORATORY MANAGED BY UT-BATTELLE FOR THE US DEPARTMENT OF ENERGY
Kenneth Kriha

Guillaume Petitpas Michael Melchionda Herie Soto Yanli Wang Zhili Feng

February 21, 2019 


\title{
DOCUMENT AVAILABILITY
}

Reports produced after January 1, 1996, are generally available free via US Department of Energy (DOE) SciTech Connect.

Website http://www.osti.gov/scitech/

Reports produced before January 1, 1996, may be purchased by members of the public from the following source:

\author{
National Technical Information Service \\ 5285 Port Royal Road \\ Springfield, VA 22161 \\ Telephone 703-605-6000 (1-800-553-6847) \\ TDD 703-487-4639 \\ Fax 703-605-6900 \\ E-mail info@ntis.gov \\ Website http://www.ntis.gov/help/ordermethods.aspx
}

Reports are available to DOE employees, DOE contractors, Energy Technology Data Exchange representatives, and International Nuclear Information System representatives from the following source:

Office of Scientific and Technical Information

PO Box 62

Oak Ridge, TN 37831

Telephone 865-576-8401

Fax 865-576-5728

E-mail reports@osti.gov

Website http://www.osti.gov/contact.html

This report was prepared as an account of work sponsored by an agency of the United States Government. Neither the United States Government nor any agency thereof, nor any of their employees, makes any warranty, express or implied, or assumes any legal liability or responsibility for the accuracy, completeness, or usefulness of any information, apparatus, product, or process disclosed, or represents that its use would not infringe privately owned rights. Reference herein to any specific commercial product, process, or service by trade name, trademark, manufacturer, or otherwise, does not necessarily constitute or imply its endorsement, recommendation, or favoring by the United States Government or any agency thereof. The views and opinions of authors expressed herein do not necessarily state or reflect those of the United States Government or any agency thereof. 
ORNL/TM-2019/1121

CRADA/NFE-16-06256

Materials Science and Technology Division

\title{
COMPRESSOR-LESS HYDROGEN REFUELING STATION USING THERMAL COMPRESSION
}

\author{
Kenneth Kriha ${ }^{1}$, Guillaume Petitpas ${ }^{2}$, Michael Melchionda ${ }^{2}$, Herie Soto ${ }^{3}$ \\ Yanli Wang ${ }^{4}$ and Zhili Feng ${ }^{4}$
}

1. Gas Technology Institute 1700 S Mount Prospect Rd, Des Plaines, Illinois 60018

2. Lawrence Livermore National Laboratory, 7000 East Avenue, Livermore California 94550

3. Shell International Exploration and Production Inc., 3333 Highway 6 South, Houston, Texas 77082

4. Oak Ridge National Laboratory, One Bethel Valley Road, Oak Ridge, Tennessee 37831

Date Published:

TBD

\author{
Prepared by \\ OAK RIDGE NATIONAL LABORATORY \\ Oak Ridge, Tennessee 37831-6283 \\ managed by \\ UT-BATTELLE, LLC \\ for the \\ US DEPARTMENT OF ENERGY \\ under contract DE-AC05-00OR22725
}

Approved For Public Release 


\section{CONTENTS}

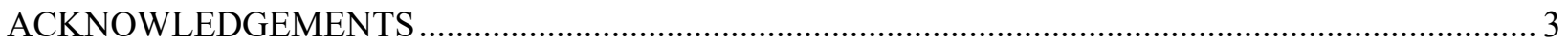

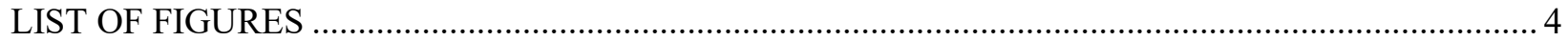

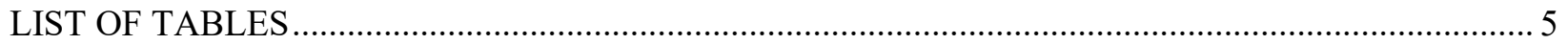

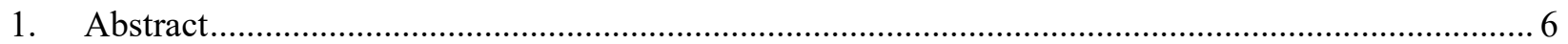

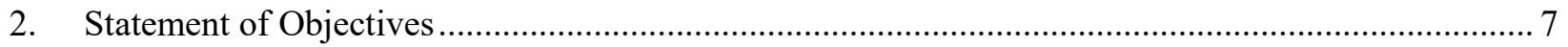

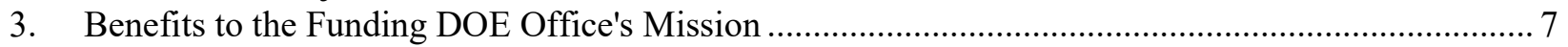

4. Technical Discussion of Work Performed by All Parties ............................................................ 8

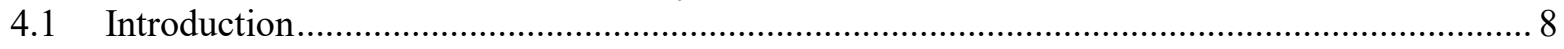

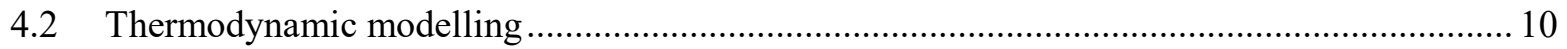

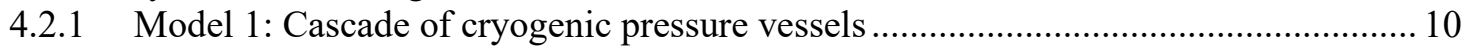

4.2.2 Model 2: Boil-off losses during low temperature $\mathrm{H} 2$ transfer .................................... 14

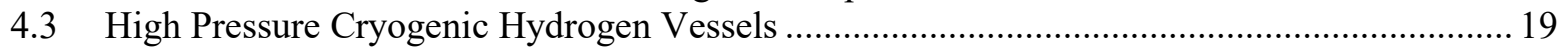

4.3.1 Requirements of the HPCHV for Thermal Compression Application........................ 19

4.3.2 Evaluation of Existing Vessels for Thermal Compression Application ...................... 21

4.3.3 Design and Cost Analysis of HPCHVs for Thermal Compression Application.......... 24

4.3.4 Summary on HPCHV study for Thermal Compression Application ............................. 30

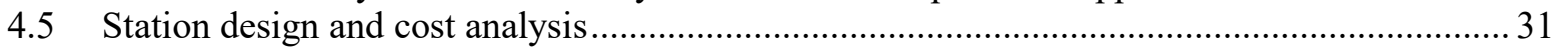

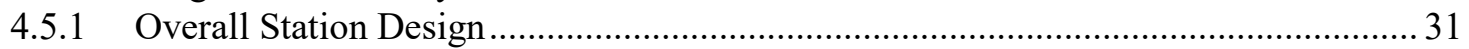

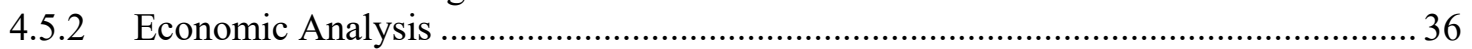

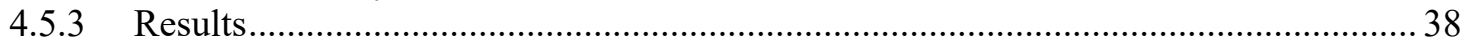

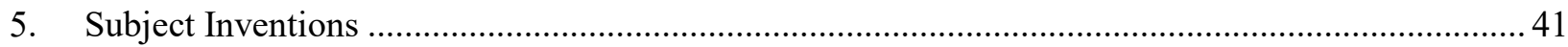

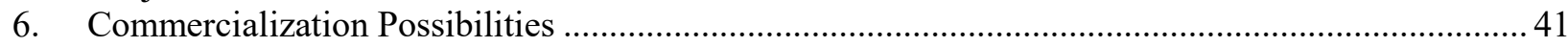

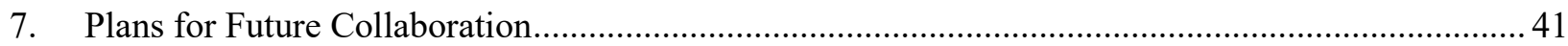

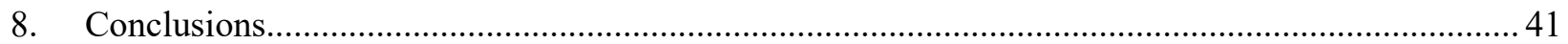

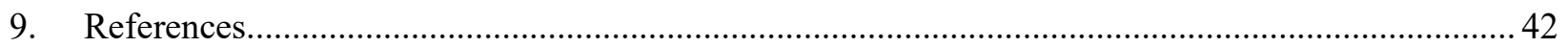




\section{ACKNOWLEDGEMENTS}

This material is based upon work supported by the U.S. Department of Energy's Office of Energy Efficiency and Renewable Energy (EERE) under the Fuel Cell Technologies Office (FCTO) under Award Number DE-EE0006966. The authors wish to acknowledge DOE program managers Erika Gupta and Neha Rustagi for guidance and oversight that were required to keep this research on track throughout the project. Part of this work was sponsored by the U.S. Department of Energy, under contract No. DEAC05-00OR22725 with Oak Ridge National Laboratory (ORNL), managed and operated by UT-Battelle, LLC, and under Contract No. DE-AC52- 07NA27344 with Lawrence Livermore National Laboratory, managed and operated by Lawrence Livermore National Security, LLC.

The authors wish to acknowledge Dr. Amgad Elgowainy from Argonne National Laboratory for his insightful inputs on this work, especially regarding the cost comparison through HDSAM. The authors appreciate the technical support from Dr. Hui Huang of ORNL for performing the Finite Element Analysis on the vessel design. 


\section{LIST OF FIGURES}

Figure 1. Differences between conventional and thermal compression hydrogen fueling stations ............. 8

Figure 2. Process steps needed for the operation of thermal compression fueling station......................... 9

Figure 3. Station demand profile for a medium size hydrogen refueling station dispensing 475 $\mathrm{kg}$ /day maximum on a summer Friday [2]

Figure 4. Cascade vessel requirement grid convergence for mínimum pressure, time off-line, and volume variables

Figure 5. Pressure traces in six cryogenic vessels (CV) as hydrogen is being dispensed into vehicles (blue dotted line). 13

Figure 6. Influence of HPCHV volume on raw material cost for cascade.

Figure 7. Illustration of the Thermodynamic States During the Thermal Compression Process Cycle ..... 15

Figure 8. Two Options for Recycling Hydrogen Back to LH2 Dewar .................................................. 16

Figure 9. Pressure and temperature variations in the Dewar as LH2 is being used and $\mathrm{H} 2$ is being recycled during a typical thermal compression station utilization, assuming top return (Left figure) or bottom return (right figure). The vertical axis shows both pressure (in psi) and temperature (in Kelvin) vs amount of $\mathrm{H} 2$ in the Dewar (in kg, horizontal axis)....... 17

Figure 10. Influence of the vapor pressure (horizontal axis) on the amount of $\mathrm{H} 2$ delivered/returned for a $200 \mathrm{~L}$ insulated pressure vessels (left vertical axis) and corresponding vent fraction (right vertical axis). Bottom return mode.

Figure 11. Pressure variations as a function of mass of $\mathrm{H} 2$ transferred in two pressure vessels: the first one is initially at $110 \mathrm{bar}, 118 \mathrm{~K}(21 \mathrm{~g} / \mathrm{L} \mathrm{H} 2$ density $)$ and it is assumed that it can not dispense $\mathrm{H} 2$ anymore thus needs to be recycled (red line); while the second vessel, initially at 3 bar, $23 \mathrm{~K}(63 \mathrm{~g} / \mathrm{L} \mathrm{H} 2$ density) was just filled with LH2 and awaits pressurization (blue line). As $\mathrm{H} 2$ is transferred from the first to the second vessel, pressure difference decreases. This calculation also assumes a $200 \mathrm{~L}$ internal volume for the pressure vessels.

Figure 12. Temperature and mass variations with and without the recovery method during the LH2 fill (continuous line: with recovery, dotted line: without recovery)..................................... 19

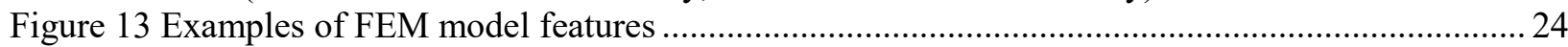

Figure 14. FEM mesh and the stresses at 900bar and $160 \mathrm{~K}$ for case I-4 _.............................................26

Figure 15. Stresses in the Aluminum liner after autofrettage at 1.25X operation pressure. ..................... 29

Figure 16. Process Flow Diagram for a 400kg/day Thermal Compressor Refueling Station.................... 32

Figure 17. 10 HPCHV section of the thermal compression station PFD showing expected maximum

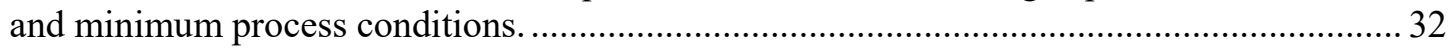

Figure 18. Dispenser Heat Exchanger and Bypass Loop ................................................................. 33

Figure 19. Valve Positions During the Thermal Compression Process .................................................... 34

Figure 20. Cost of pressure vessels as function of the inner volume (6 in. inner diameter, 900 bar rated pressure). The vaccum jacket cost using MLVS is also included. ................................. 35

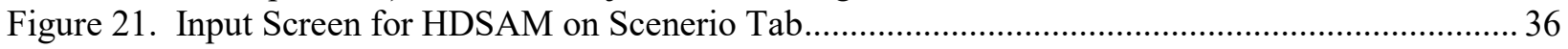

Figure 22. Dewar pressure and boil-off variations as a function of the amount of $\mathrm{H} 2$ delivered to the vehicle, for a thermal-compression refueling station, using steel lined type III vessels and recovery methods. The Dewar is $22.7 \mathrm{~m} 3$ and initially hold $1608 \mathrm{~kg}$ of LH2 at 20 psia.

Figure 23: Boil-off during operation of a station using a thermal-compression concept, for a Type II-4B-Ni pressure vessel design, assuming mid production levels. 


\section{LIST OF TABLES}

Table 1. Survey of existing different types of inner vessel for thermal compression application .............. 22

Table 2. Feasibility of existing vessels for thermal compression application......................................... 23

Table 3. Type 1 Vessel Design using SS316 ................................................................................25

Table 4 Overall cost estimates and underlining assumptions for Type 1 HPCHVs .................................2 27

Table 5 Overall cost estimates and underlining assumptions for Type II vessel ......................................28

Table 6 Summary of potential HPCHV design options for use in the thermal compression station. Numbers are given here for a $200 \mathrm{~L}$ inner volume, 6 in. inner diameter and 900 bar rated pressure vessel. (Table will need to be updated)

Table 7. Capital Cost Breakdown for Convention Hydrogen Refueling Station ...................................... 37

Table 8. Summary of levelized cost break down for conventional fueling station case ........................... 37

Table 9. Equipment eliminated from conventional hydrogen fueling stations ........................................ 38

Table 10. Capital cost input for thermal compression station................................................................. 39

Table 11. Capital cost comparison between convention and thermal compression stations..................... 39 


\section{ABSTRACT}

The goal of this project was to demonstrate the technical and economic feasibility of using thermal compression to create the hydrogen pressure necessary to operate vehicle hydrogen fueling stations. The concept of utilizing the exergy within liquid hydrogen to build pressure rather than mechanical components such as compressors or cryogenic liquid pumps has several advantages. In theory, the compressor-less hydrogen station will have lower operating and maintenance costs because the compressors found in conventional stations require large amounts of electricity to run and are prone to mechanical breakdowns. The thermal compression station also utilizes some of the energy used to liquefy the hydrogen as work to build pressure, this is energy that in conventional stations is lost as heat to the environment.

The project consisted of the following steps:

- Create a transient thermodynamic model of the thermal compression station.

- Research and design High Pressure Cryogenic Hydrogen Vessels (HPCHVs) that would be capable of withstanding the thermal compression cycle.

- Design the thermal compression station to generate a process flow diagram and ultimately a major component equipment list.

The completion of these three tasks defined the capital and operational expenses of the thermal compression station and allowed for the economic comparison with the conventional hydrogen fueling station.

The economic comparison between the thermal compression and a conventional station utilizing a compressor was analyzed using the Hydrogen Delivery Scenario Analysis Model (HDSAM) [1]. This model, developed by Argonne National Laboratory, was used to determine the total levelized station cost. The levelized station cost, in dollars per kilogram of delivered hydrogen to vehicles at the station, takes into account all the costs associated with the refueling station including capital, operating, energy, and maintenance.

The economic information of the conventional station was taken directly from HDSAM version 3.0, which was released in 2016. Economic analysis of the thermal compression station came from a modified version of HDSAM that accounts for both the unique equipment requirements and the operational and maintenance differences that result from using the thermal compression station.

The go-no/go decision criterion for this project was to show that a thermal compression station could have a $15 \%$ economic advantage over a similarly sized conventional station. In order to complete this comparison, a station capacity of $400 \mathrm{~kg}$ /day was chosen. In a conventional station of this capacity, the pressure needed for fueling hydrogen powered vehicles is generated using either a compressor or a cryogenic liquid pump. For this feasibility study, the thermal compression station was compared to a conventional station equipped with a hydrogen compressor. The station is required to be able to satisfy a hourly varying refueling profile that is based on real life measured refueling data, and often used in DOE's analyses [2].

The results of the project showed that the thermal compression fueling station could not meet the $15 \%$ cost reduction criteria. The project did show that the thermal compression station did provide an advantage on the initial capital expense, but this advantage was overcome by the hydrogen losses that accrue during the thermal compression process. Attempts were made to refine and optimize the process, but even with the most optimistic design, the thermal compression station could only offer a $6 \%$ reduction in delivered $\mathrm{H} 2$ costs when compared to a conventional station. 


\section{STATEMENT OF OBJECTIVES}

This is a collaborative effort between DOE Contractors (Lawrence Livermore National Security, LLC manager and operator of Lawrence Livermore National Laboratory (LLNL) and UT-Battelle, LLC, manager and operator of Oak Ridge National Laboratory (ORNL)); and Participants Shell Global Solutions (US) Inc. (Shell), and (Gas Technology Institute (GTI), to study the feasibility of a Compressor-less Hydrogen Refueling Station using Thermal Compression.

This project aims to demonstrate the technical and economic feasibility of the thermal compression concept for compressor-less refueling stations. The specific goals are the following: determine the most cost-effective insulated pressure vessel design for the application, build transient simulation models to be used for station design, carry out a preliminary full scale system design, and validate the key concepts using a small-scale demonstration experimental system. The achievement of these goals will enable the project team to deliver an overall techno-economic study of the concept with the expected outcome of total station cost (capital and operating) reduction of at least 15\% (baseline total levelized station cost: $\$ 8.72 / \mathrm{kg}^{1}$.

\section{BENEFITS TO THE FUNDING DOE OFFICE'S MISSION}

A strong team was brought together with expertise and experiences necessary to complete the project goals.

LLNL brings in its expertise in terms of cold and pressurized hydrogen thermodynamics simulation and engineering, and looks forward to develop cost-effective tank design and station integration of the thermal compression concept.

ORNL is the inventor of the innovative steel concrete composite vessel (SCCV) technology specifically designed and engineered as a cost-effective solution for stationary high-pressure gaseous hydrogen storage applications. The SCCV technology would be readily scaled up to 875 bar, and meet or exceed the DOE's 2020 cost target of stationary high-pressure storage for the pressure levels specified in the FCTO's MYRD\&D plan. In this project, the SCCV will be further refined as one of the storage vessel options to achieve total cost effectiveness of the compressor-less fueling station technology.

Shell currently operates five hydrogen stations in California and Germany and in the past it has been involved in the operation of more stations in other parts of the world. Two of the stations use liquid hydrogen as the source of supply and one of these stations, in Berlin, is the world's largest combined passenger vehicle and bus hydrogen refueling station, designed for a $1000 \mathrm{~kg} /$ day capacity. These stations have allowed Shell to evaluate from a technical and economical aspect a range of station technologies, understand and drive down operation and maintenance costs, improve equipment reliability, as well as to

\footnotetext{
${ }^{1}$ Cost estimate obtained using a preliminary (not released) hydrogen refueling simulation tool from Argonne National Laboratory (conversations with A. Elgowainy- March 2015), for the following refueling station scenario: dispensing capacity $400 \mathrm{~kg}$ /day, liquid $\mathrm{H} 2$ delivery, room temperature 700 bar refueling via compressor. Corresponding baseline costs (in \$2013) are: \$1,900,000 Total Initial Capital Investment, equivalent to a capital levelized station cost of $\$ 5.67 / \mathrm{kg}$ and an operating \& maintenance cost of $\$ 3.05 / \mathrm{kg}$ (total: $\$ 8.72 / \mathrm{kg}$ )
} 
have a better understanding of consumer behavior. For this project Shell will bring the expertise and knowledge gained with the operation of these stations.

GTI has more than 70 years of R\&D experience and strives to develop new concepts into systems ready to be introduced into industry. For this project, GTI will provide industrial expertise in fueling station design, pressure vessel testing, and, as the lead recipient, project management.

\section{TECHNICAL DISCUSSION OF WORK PERFORMED BY ALL PARTIES}

\subsection{INTRODUCTION}

The concept of using thermal compression in hydrogen refueling stations was introduced by Petitpas [3] in 2012. This paper discussed the potential advantages of using the thermomechanical exergy within liquid hydrogen as the energy to create the pressure needed in hydrogen fueling storage cascades. Figure 1 illustrates the differences between a conventional hydrogen refueling station and a thermal compression fueling station. The figure shows that in a thermal compression fueling station there is no need for a compressor or refrigeration chiller. The elimination of this equipment would not only reduce the initial capital investment in the station but it would also reduce the operational and maintenance costs since this mechanical equipment is prone to breakdowns.
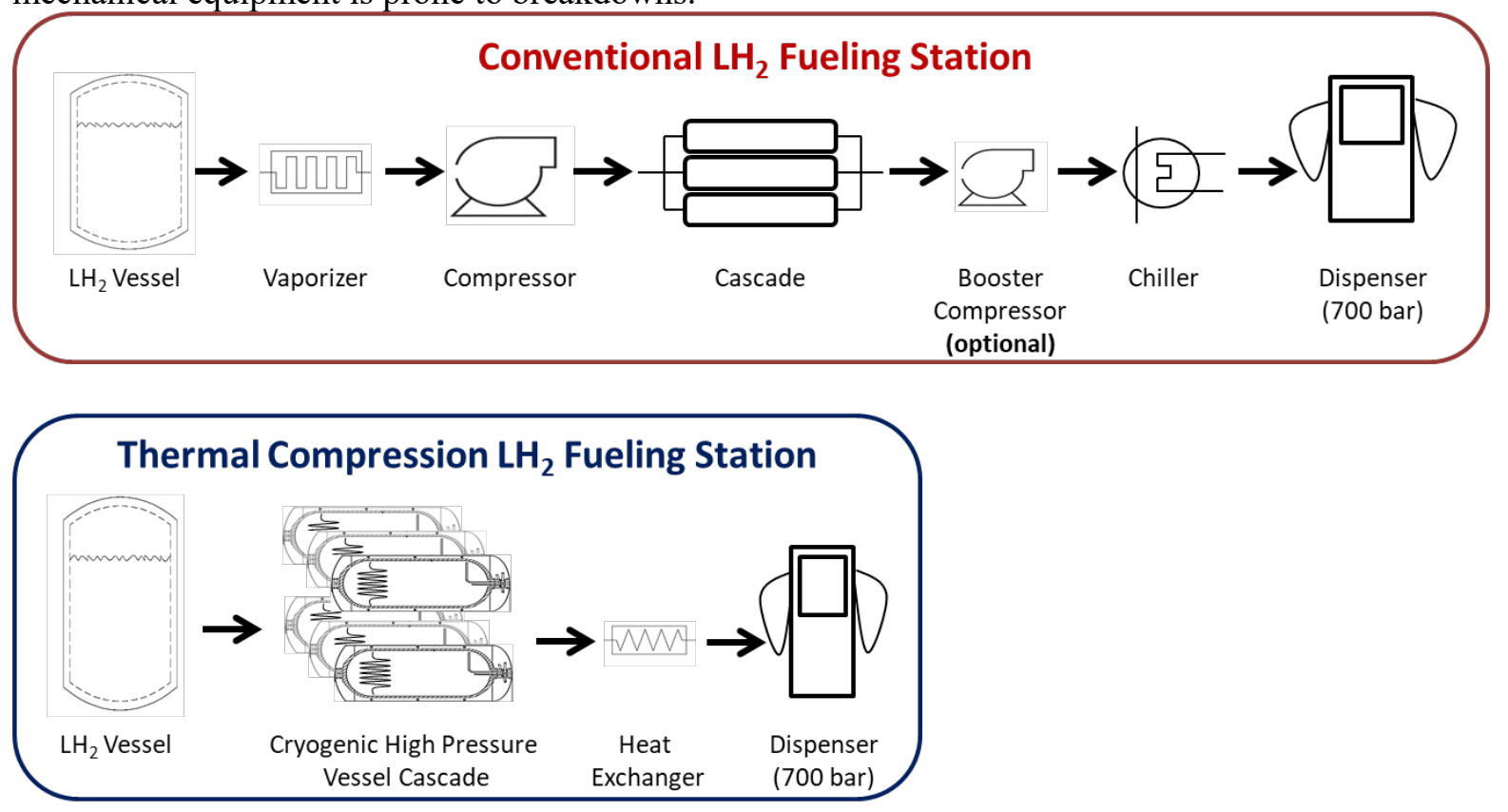

Figure 1. Differences between conventional and thermal compression hydrogen fueling stations

The study also defined the operational steps that would be needed to employ the thermal compression station. Figure 2 illustrates the process steps of the thermal compression station. During the course of the project the physical equipment needed to carry out some of the steps were modified, but the functions performed in each step remained the same.

Step 1 - Fill HPCHV with LH2

In Step 1 LH2 is transferred from the LH2 storage Dewar to the HPCHV. The transfer is carried out via pressure differential between the Dewar and HPCHV. During the transfer, the cold liquid enters a relatively warm vessel thus rapidly changes phases from liquid to gas. This boil off gas must be removed from the vessel in order to maintain the pressure in the vessel below the Dewar pressure so liquid flow 
can be maintained. Eventually, the HPCHV cools to a low enough temperature to accept and hold the hydrogen as a liquid within the vessel.

Step 2 - Add Heat to the HPCHV to Increase Pressure

Once the HPCHV is full of LH2, the vessel is isolated from the Dewar. Heat will then be introduced to the vessel in order to start the pressure building process. Figure 2 depicts $\mathrm{H} 2$ from another vessel being used as a heat carrier, later in the project this approach was abandoned in lieu of an ambient temperature heat exchanger.

Step 3 - Employ the HPCHV in Vehicle Fueling Cascade

When the HPCHV reaches the target dispensing pressure of 900 bar, the temperature of the $\mathrm{H} 2$ within the vessel will be around $160 \mathrm{~K}(-113 \mathrm{C})$. The hydrogen will have to be warmed up to the dispensing temperature of $-40 \mathrm{C}$ before it is delivered to the vehicles. The HPCHV will participate in the vehicle fueling operation until the pressure in the vessel decreases to the point where it can no longer significantly contribute to increasing the pressure in the vehicle. This pressure is a variable in the thermodynamic model which was developed.

Step 4 -Recycle Some Hydrogen from the HPCHV to the Dewar

The hydrogen remaining in the HPCHV after Step 3 must be removed in order for the vessel to be refilled with LH2. Some of this hydrogen is directed back to the LH2 Dewar in order to increase the pressure in the Dewar to provide the pushing force for the liquid to be delivered to the next HPCHV in line to be filled. This lowers the pressure in the HPCHV, but not below the pressure of the Dewar.

Step 5 - Vent Remaining $\mathrm{H} 2$ in HPCHV

The final step in the thermal compression process is to vent the remaining hydrogen in the HPCHV. This low pressure, low density hydrogen is not useful for fueling vehicles, it may have value as a fuel for stationary fuel cells or site heating needs.
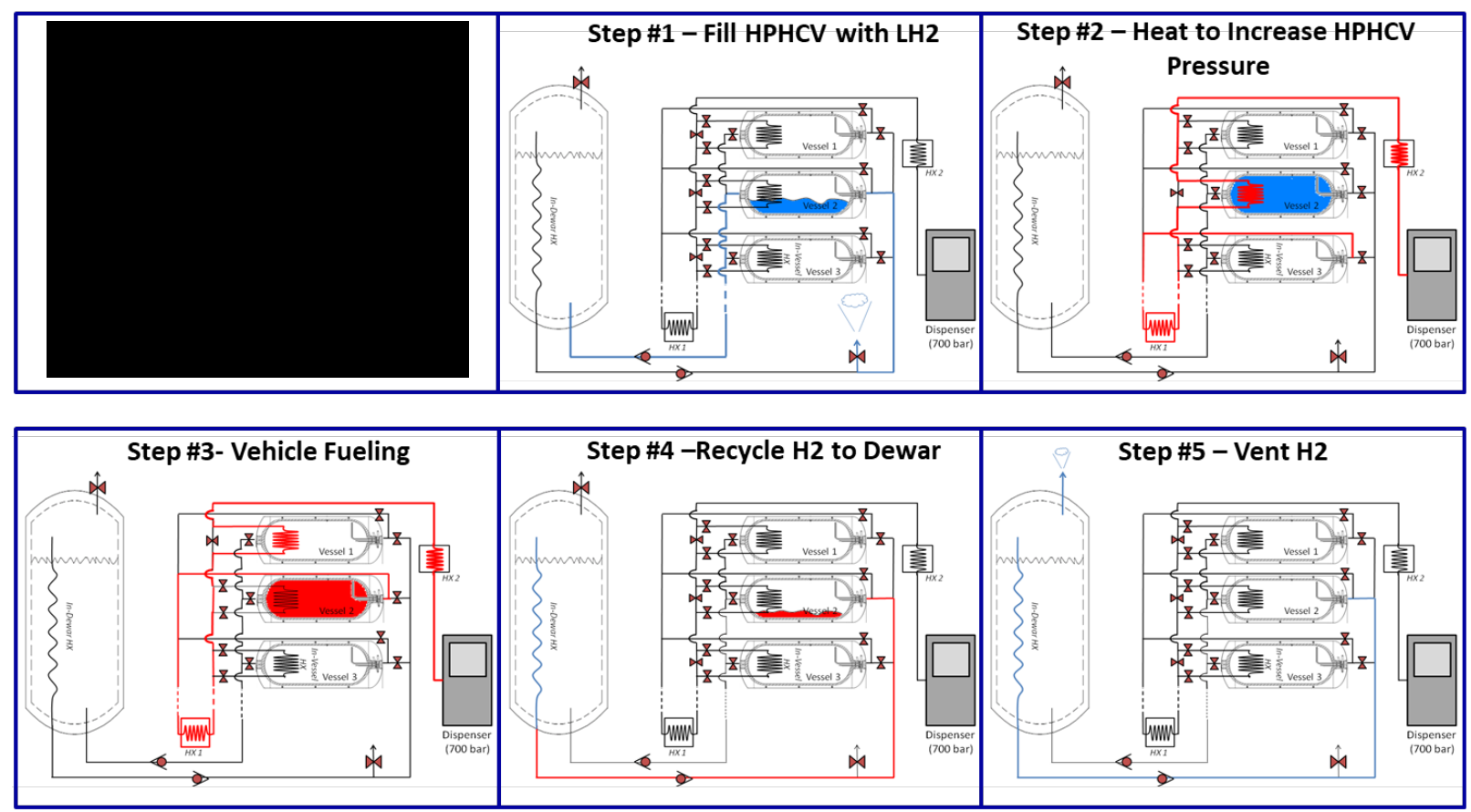

Figure 2. Process steps needed for the operation of thermal compression fueling station

The 2012 paper did include some thermodynamic modeling and economic analysis, this project set out to perform a more rigorous investigation into the technical and economic feasibility of a hydrogen fueling station using thermal compression. The project consisted of the following steps:

- Create a transient thermodynamic model of the thermal compression station. 
- Design the thermal compression station to generate a process flow diagram and ultimately a major component equipment list.

- Research and design pressure vessels that would be capable of withstanding the thermal compression cycle.

\subsection{THERMODYNAMIC MODELLING}

A model is needed in order to simulate the thermal compression station from a thermodynamic standpoint. The goal of the modeling effort is to:

1. Evaluate the number and size of pressure vessels needed to meet the station demand - which would control capital cost.

2. Evaluate the relationship between venting losses and station design/operation - which would control operational cost.

The most cost effective overall design can be obtained by optimizing these capital and operational costs. In this section, the thermodynamic modeling framework for the thermal compression station design is presented and the main characteristics of how such a station would operate is explored. Details concerning how the model was used for cost optimization are presented later in Section 3 of this report. Two separate models were developed. The first one computes the number of vessels needed to meet the station demand given a certain design for the HPCHV (internal volume, rated pressure, diameter, material, estimated time to refill). The station demand is simulated to be able to satisfy a hourly varying refueling profile that is based on real life measured refueling data, and often used in DOE's analyses [2]. The second subroutine evaluates the amount of $\mathrm{H}_{2}$ that will be wasted to atmosphere when the pressure vessel goes through a typical fill/warm-up/dispensing/emptying loop; given, again, a certain design for the pressure vessel and also the overall station (Dewar size and level of fill, Dewar's maximum operating pressure).

The simulation design is based on the first law of thermodynamics (conservation of mass and energy), and assumes that the $\mathrm{H}_{2}$ temperature is uniform in each vessel, and is at equilibrium with the vessel walls. Real gas equations of states are considered, as well as 2-phase behavior, using the REFPROP package from NIST [4].

\subsubsection{Model 1: Cascade of cryogenic pressure vessels}

The thermal compression station will deliver hydrogen only from a cascade (or "buffer") of insulated pressure vessels. This cascade has to be carefully designed in order to meet the daily demand at the station, using parameters such as number, size (=internal volume), pressure rating and material for the pressure vessels. The daily demand at the station met the profile derived from data consolidated from 387 hydrogen fueling stations that produced hourly distributions of refueling events [2]. A transient thermodynamic model was thus built to make sure that the cascade of insulated pressure vessels could meet the daily demand for the most extreme case, i.e. a Friday in the summer - see Figure 3. Please note that this approach is typically used for hydrogen station refueling cost estimates, such as the work from A. Elgowainy's group [5], [6]' [7]. 


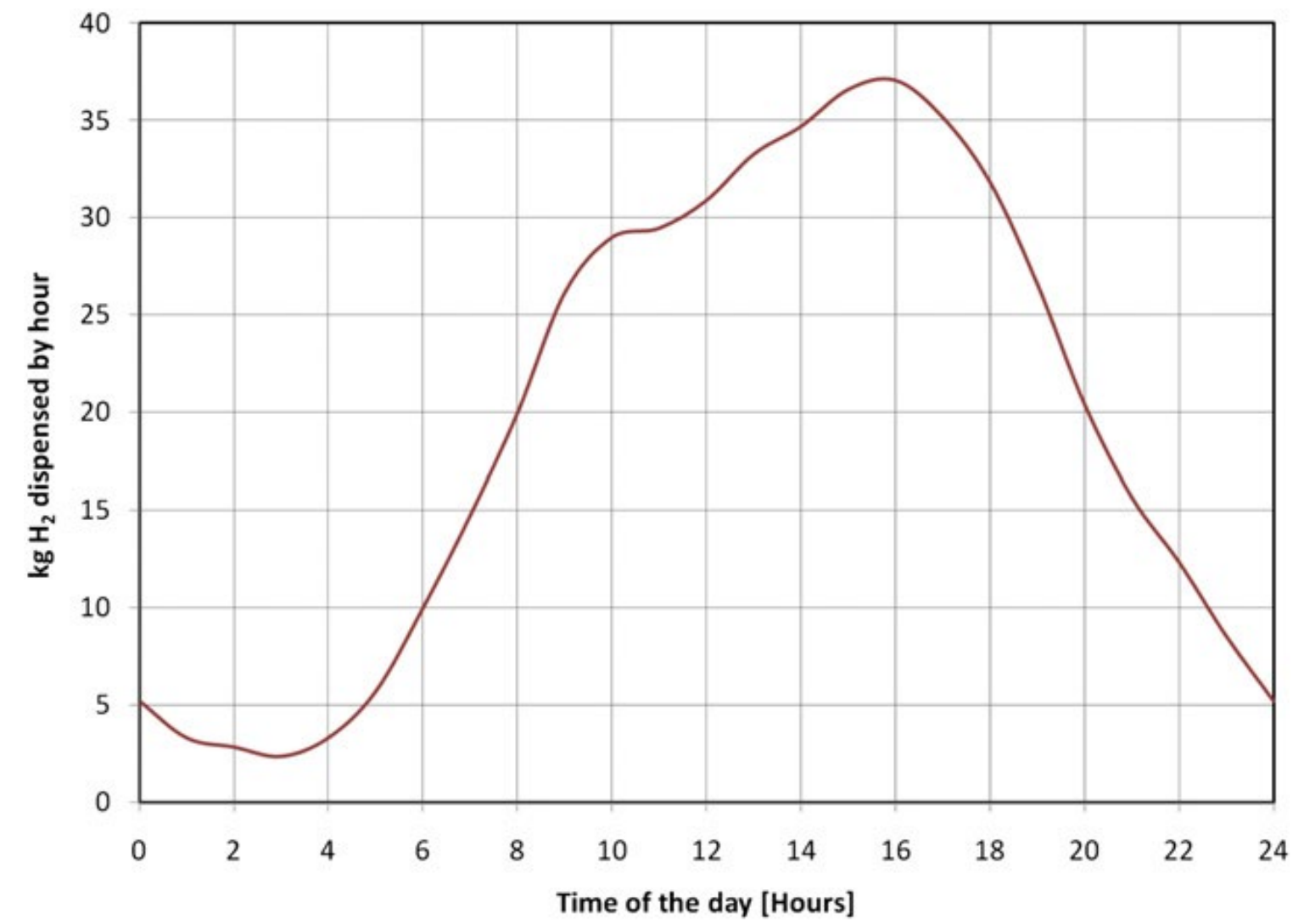

Figure 3. Station demand profile for a medium size hydrogen refueling station dispensing $475 \mathrm{~kg} / \mathrm{day}$ maximum on a summer Friday [2]

For this transient model, a few assumptions are considered, in line with comparable state-of-the-art studies to enable fair comparisons:

- FCEVs are equipped with a 700 bar, $5.6 \mathrm{~kg} \mathrm{H} 2$ usable capacity storage tank (140 L internal volume),

- The minimum dispensing temperature at the break-away is -40 C (compliance with J2601 T40 protocols [8],

- FCEVs comes to the station with $1 \mathrm{~kg} \mathrm{H} 2$ remaining, so that the initial conditions in the tank at the beginning of the fill are 90 bar at ambient temperature,

- The cascade is connected to a two-hose dispenser that can simultaneously refuel two vehicles. The hydrogen flow rate per hose is $1.67 \mathrm{~kg} / \mathrm{min}$, and the total cascade flow rate is $3.34 \mathrm{~kg} / \mathrm{min}$

- The cascade dispenses from the least pressurized cryogenic vessel that (1) is at a higher pressure than the vehicle vessel, and (2) is not being thermally pressurized,

- Refueling from a cryogenic vessel ends when the pressure difference between the vessel and the tank in the car $\left(\mathrm{P}_{\text {cryogenic }}-\mathrm{P}_{\text {vehicle }}\right)$ equals 1.4 bar. At this point, refueling continues from the next higher pressure cryogenic vessel not being pressurized until the vehicle vessel is full $(5.6 \mathrm{~kg} \mathrm{H} 2)$

- FCEVs are refueled at the beginning of each hour, in a back-to-back mode

A Fortran code was written in order to simulate the dispensing from the cascade of insulated pressure vessels to the FCEVs. The overall time window of operation could be set to as much as a couple of weeks, and pressure vessels were added to the cascade as needed to meet the demand when all other vessels were considered unavailable (too low pressure or being filled with LH2). 
Assuming a fixed station capacity (400 kg/day), the following parameters can be easily adjusted:

- Time window of operation

- $\quad$ Pressure rating (700 to 900 bar)

- Internal volume (100 to $2000 \mathrm{~L})$

- "Time-off" duration, i.e. time during which the vessels are being filled with LH2 and thus cannot be used for dispensing (30 minutes to 2 hours)

- Minimum pressure in the vessel at which $\mathrm{H} 2$ can still be dispensed (90 to 150 bar). The assumption is FCEVs that come to the station have $1 \mathrm{~kg}$ left in their tank, thus a pressure of 90 bar. Ideally, each vessel should be used until this lower limit. However, this may mean that some vessels may be kept in the "available" group for a very long time, dispensing only a few grams in each FCEV, ending up having to add additional pressure vessels to the cascade in order to meet the demand. A higher termination pressure would of course mean that the vessel is under-utilized, but may lead to faster turn-around time.

- Tank material. Vessels can be all metal (Type I) or overwrapped with composite materials (Type II to IV). The model was built such that the masses of most common materials (steel, aluminum, carbon fiber, fiber glass) could be entered as inputs, using correlations from the literature for their respective heat capacities.

The model was verified using a set of multiple runs over extended time windows of operation, these verification runs established a baseline of the minimum values. Due to the lack of experimental data available, the validity of the model results were judged mainly based on physical "sense" and making sure all balances were respected. Indeed, the steady state operation will be a strong function of the initial quantities of $\mathrm{H} 2$ in each of the various pressure vessels.

Figure 4 shows this grid convergence study, where all the vessels are initially at their maximum pressure and minimum temperature, i.e. maximum $\mathrm{H} 2$ density. Each day of operation is considered a summer Friday, and initial time is $5 \mathrm{PM}$. The model continues to increase the number of vessels in the cascade for each case until eventually the number of vessels reaches a constant value. This constant value is the vessel requirement to meet the station demand need for the specific parameters of minimum vessel pressure, time off-line to recycle/recharge, and volume of each storage cylinder. 


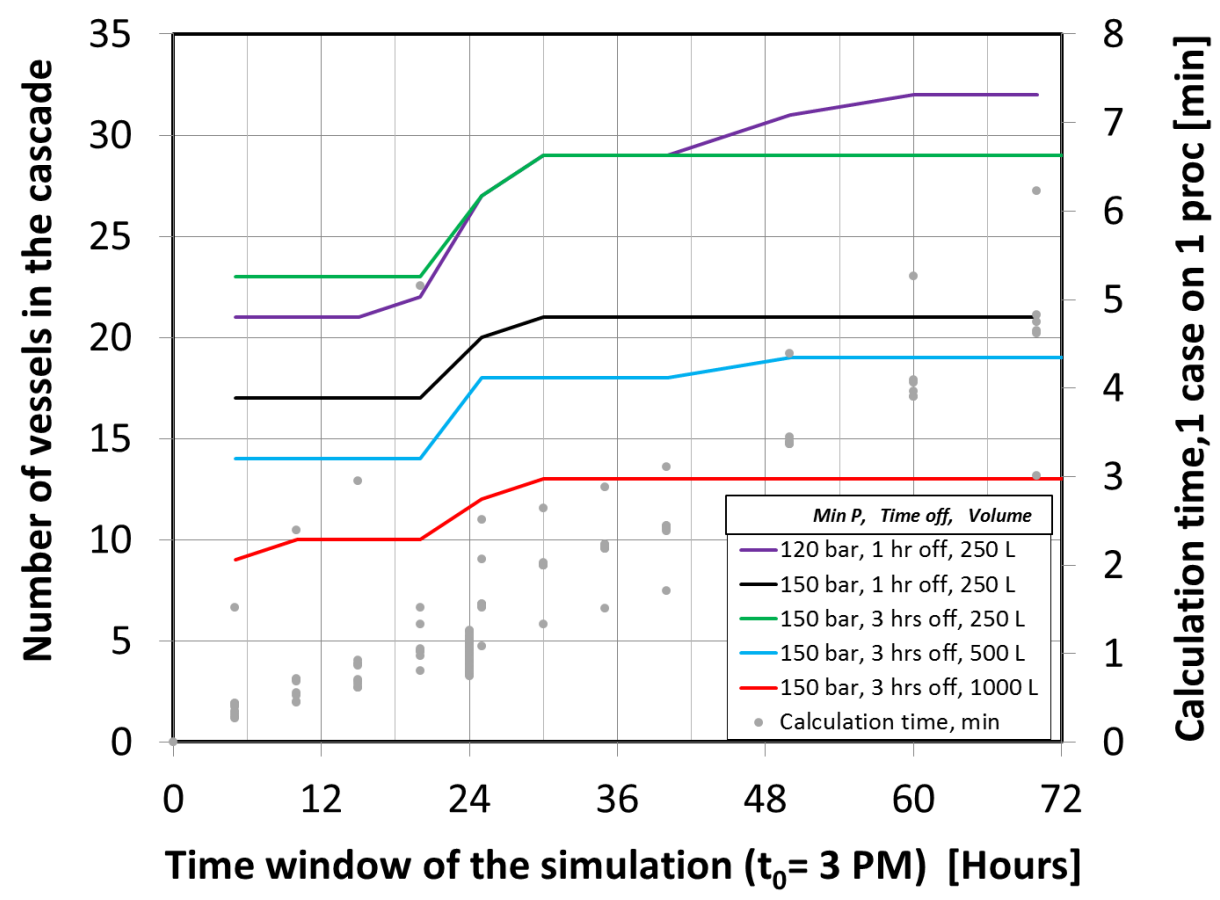

Figure 4. Cascade vessel requirement grid convergence for mínimum pressure, time off-line, and volume variables

Figure 5 shows a pressure trace of six of the high pressure hydrogen cryogenic vessels (labeled as CV1 to CV6 in the figure) as they operate in the fueling station cascade. In this trace, each vessel starts out at its maximum capacity. The dotted blue lines represent the pressure in the vehicle connected to the dispenser. This trace shows after the $3^{\text {rd }}$ vehicle has refueled, CV1 is taken off-line and refilled. The thermodynamic model keeps track of the pressure and temperature in each cascade vessel in order to calculate the required number of vessels required to meet vehicle demand.

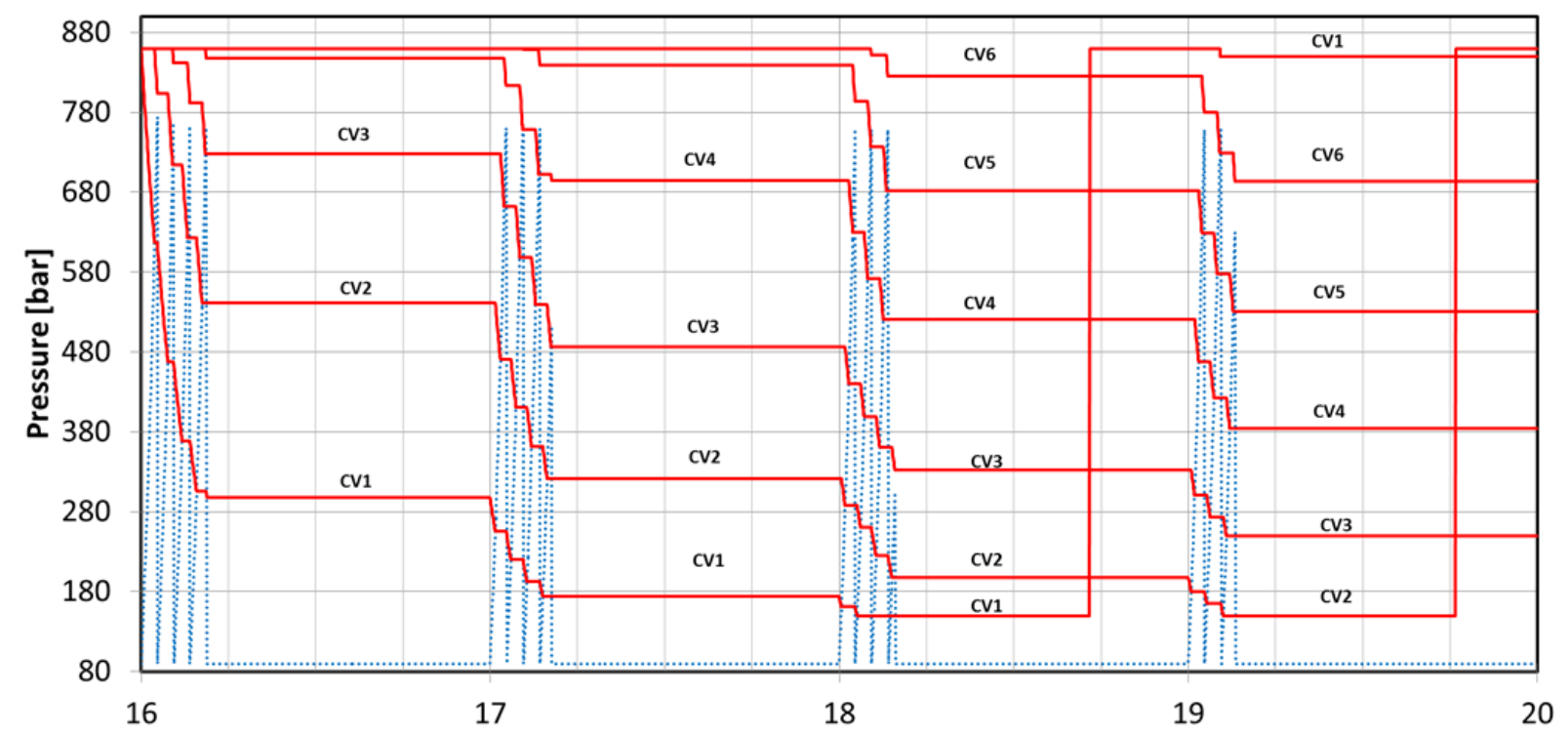

Figure 5. Pressure traces in six cryogenic vessels (CV) as hydrogen is being dispensed into vehicles (blue dotted line).

Once the cascade of pressure vessel model was completed and verified, variables were adjusted to study the impact of physical and operational parameters on the quantity of cascade vessels required. Figure 6 shows how the model can be used to select optimal vessel volumes for the variables of minimum pressure 
and time off-line. Figure 6 also shows how the model can be used to gather economic data. In this case, the volume was plotted against Type III raw material cost of each HPCHV.

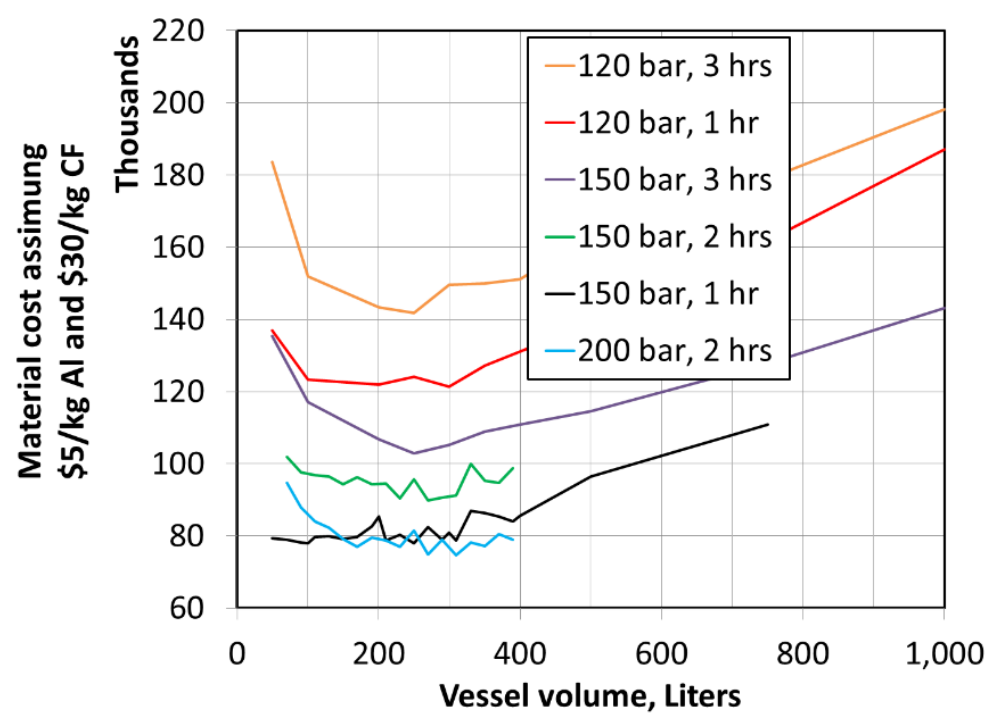

Figure 6. Influence of HPCHV volume on raw material cost for cascade

One of the first results of the modeling work came from running the "transient cascade sizing" routine, where it became apparent that an overall station design with many vessels of small volumes (as opposed to a few very large vessels) would be more favorable. The smaller vessels maximize the utilization rate of each vessel by allowing a more rapid emptying per vessel. That result can be seen on Figure 6, where various switch pressure, times off-line and vessel volume values are tested for optimal design, ultimately using total material cost as the performance metrics.

\subsubsection{Model 2: Boil-off losses during low temperature $\mathrm{H} 2$ transfer}

Once an insulated pressure vessel cannot be used any more to fill FCEVs (its pressure equals the minimum value set for the design), it needs to be emptied to a low-pressure value (Process Steps 4 and 5), then cooled-down in order to be re-filled with LH2. Indeed, the concept works under the assumption that a LH2 pump cannot be used and the LH2 flow occurs only by pressure differential between the storage Dewar and the insulated pressure vessel. Large cryogenic liquid hydrogen storage Dewars are typically rated and operated at low pressures (1.5 to 5 bar); therefore, in order to flow liquid hydrogen into the HPCHV, the pressure in the insulated vessel needs to be reduced below that Dewar pressure. Additionally, the insulated pressure vessel will need to be cooled down to allow liquid hydrogen to accumulate in the HPCHV. If the vessel is too warm, the molecules of LH2 flowing in will instantly vaporize and pressurize, canceling the pressure difference thus blocking the flow. Some vessel cool down takes place when the pressure in the insulted pressure vessel is released, through an isentropic vent. However, more cooling is needed to bring the vessel down to LH2 temperatures. This cooling can be achieved by flowing LH2 through the pressure vessel, letting the vaporized LH2 escape. 


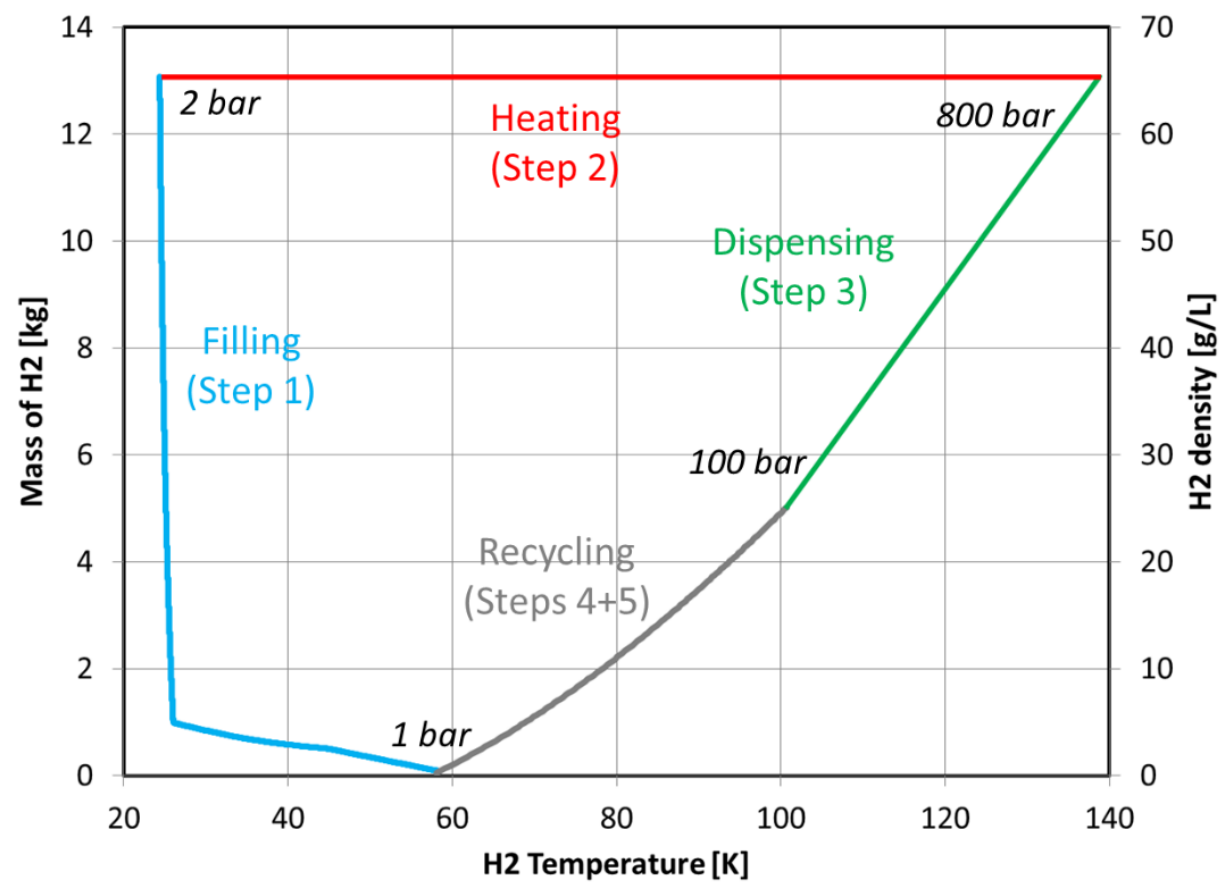

Figure 7. Illustration of the Thermodynamic States During the Thermal Compression Process Cycle

Figure 7 shows the thermodynamic states an insulated pressure vessel goes through during the thermal compression process. The mass and the density of $\mathrm{H} 2$ within a vessel with an internal volume of $200 \mathrm{~L}$ are represented on the two vertical axis, and $\mathrm{H} 2$ temperature is on the horizontal axis. The vessel is first filled with LH2 at low pressure and low temperature until it reaches it maximum capacity (Step 1), then is being heated at constant capacity up to its rated pressure (Step 2), before being used to dispense to the FCEVs (Step 3). Once the pressure is too low, the $\mathrm{H} 2$ in the vessel is recycled or vented away (Step 4 and 5), to undergo LH2 cooling and filling in Step 1.

Venting losses occur in steps 1 and 5. Flow strategies between the various vessels can be implemented to minimize those losses:

- Venting H2 vapor back to the Dewar. This would take advantage of the large mass of very cold (20 to $30 \mathrm{~K}$ range) high-density LH2 to cool-down the boil-off $\mathrm{H} 2$;

- Recycling "warm" H2 vapor. A pressure vessel that is in Step 4 (recycling) can vent some of its $\mathrm{H} 2$ to a pressure vessel that is in Step 2 (heating): "topping" off that vessel would increase its density (thus lower its temperature for a given maximum pressure), lower the amount of wasted $\mathrm{H} 2$ from Step 4, and reduce the amount of energy needed in Step 2;

- Recycling "cold" H2 vapor. Another boil-off recovery strategy consists in venting the very cold vapor $(<30 \mathrm{~K})$ from Step 1 to another vessel that awaits to be refilled, thus lowering its temperature.

Each of those boil-off recovery methods are discussed below.

In Step 4, H2 can be returned either to the top of the Dewar, in its vapor space, or to the bottom of the Dewar, through the liquid space. Figure 8 summarizes the two options for returning hydrogen back to the LH2 Dewar. The two options will have drastically different effects on the temperature and pressure behavior of the Dewar. The top return option will keep the liquid phase at constant and cold temperature, almost independently from the variations in the conditions of the vapor space, where the recycled $\mathrm{H} 2$ is returned. In this case, from a modeling standpoint, the Dewar can be simulated as a two phase system with an interface [9]. The bottom return option, on the other hand, assumes thermal equilibrium between the two phases and the Dewar is modelled as one single zone. 


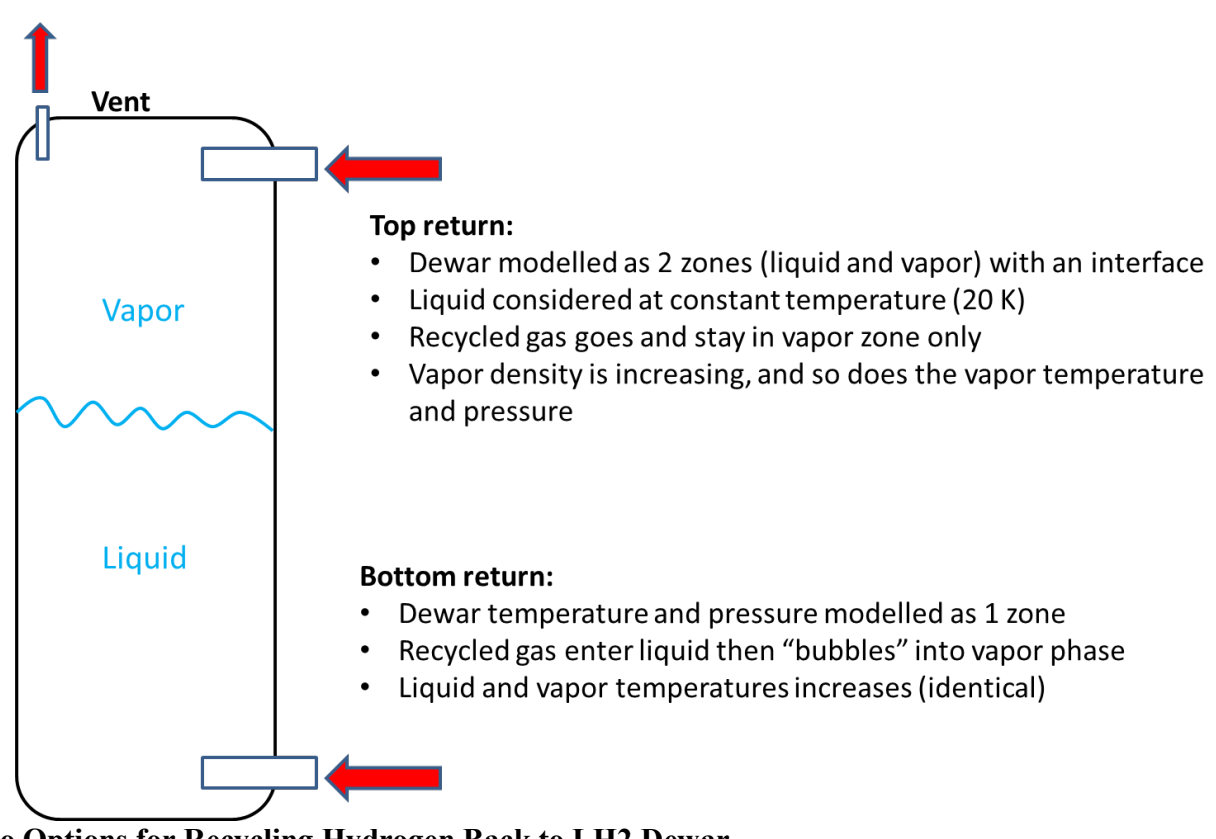

Figure 8. Two Options for Recycling Hydrogen Back to LH2 Dewar

Figure 9 shows the pressure and temperature variations for both the top and bottom return options, left and right graphs respectively. Both pressure (in psi) and temperature (in Kelvin) are showed in the vertical axis, vs. amount of $\mathrm{H} 2$ in the Dewar (in kg, horizontal axis). The figures should be read from left to right, as the LH2 from the Dewar is being used. Both cases (top and bottom return) start at the same pressure and temperature. The sawtooth profile comes from the liquid extraction/vapor return design: the vapor pressure decreases when LH2 is extracted to fill a HPCHV, while vapor pressure increases when vapor $\mathrm{H} 2$ returns during step 4 . For the top return method, the vapor pressure increases overall as more $\mathrm{H} 2$ is being recycled onto the Dewar throughout station utilization, reaching $700 \mathrm{psi}$ (for a vapor pressure of $55 \mathrm{~K}$ ) when the Dewar is virtually empty. During that utilization, the liquid temperature (not showed) stayed at a constant value of $20 \mathrm{~K}$. For the bottom return option, the vapor pressure increases only up to $100 \mathrm{psi}$ and the overall temperature to less than $30 \mathrm{~K}$. Even though those values would change depending on the different parameters used (volume of Dewar, initial pressure and temperature, amount of LH2 used and of vapor $\mathrm{H} 2$ recycled...), it is assumed that the behaviors described here are inherent to those 2 methods:

- A top return would lead to significant Dewar pressurization, and minimum LH2 temperature thus highest delivered density

- A bottom return would enable lower pressurization, lower vapor temperature but higher LH2 temperatures

Based on those observations, especially regarding the significant pressurization for the top return method, it was decided to only consider bottom return for the rest of this work. Note that venting losses occur during the cases shown in Figure 9. During the LH2 extraction for example, some $\mathrm{H} 2$ is vaporized at a lower pressure than the Dewar pressure, thus cannot be returned to the Dewar. 

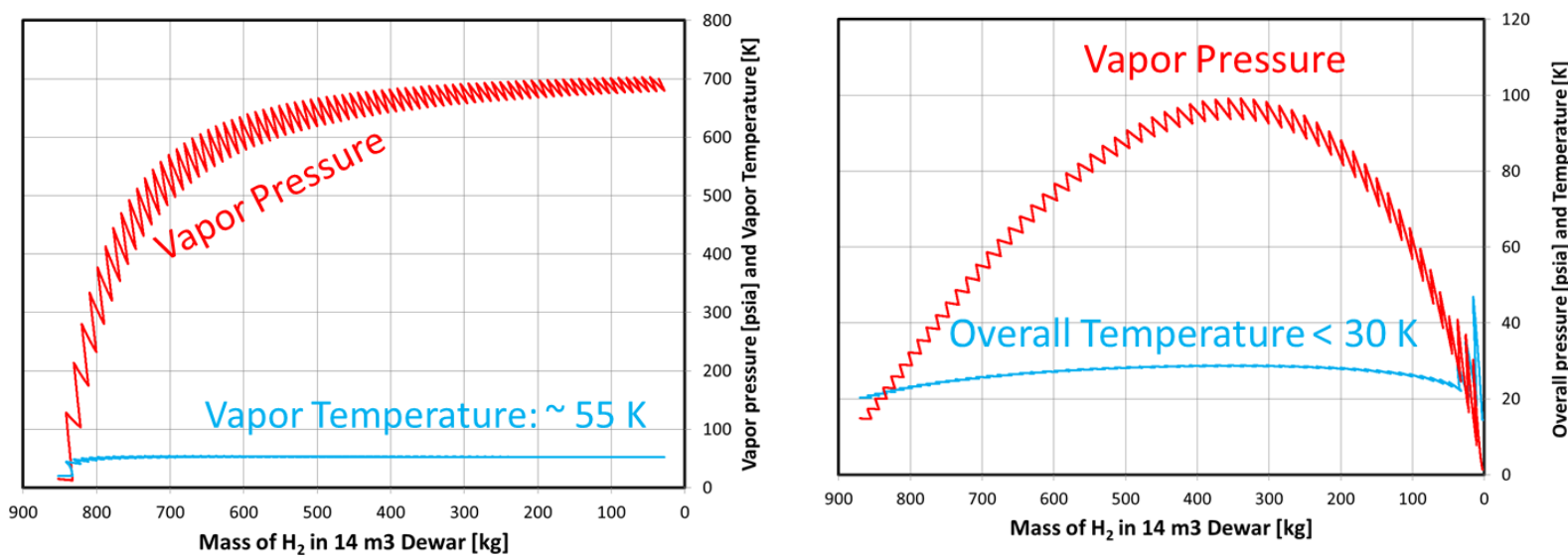

Figure 9. Pressure and temperature variations in the Dewar as $\mathrm{LH} 2$ is being used and $\mathrm{H} 2$ is being recycled during a typical thermal compression station utilization, assuming top return (Left figure) or bottom return (right figure). The vertical axis shows both pressure (in psi) and temperature (in Kelvin) vs amount of $\mathbf{H 2}$ in the Dewar (in kg, horizontal axis).

Various combinations of $\mathrm{H} 2$ quantities, vapor pressure and overall temperature were simulated, and it was found that the vapor pressure was the sensitive parameter controlling the venting losses. Figure 10 shows the influence of vapor pressure on the vent fraction.

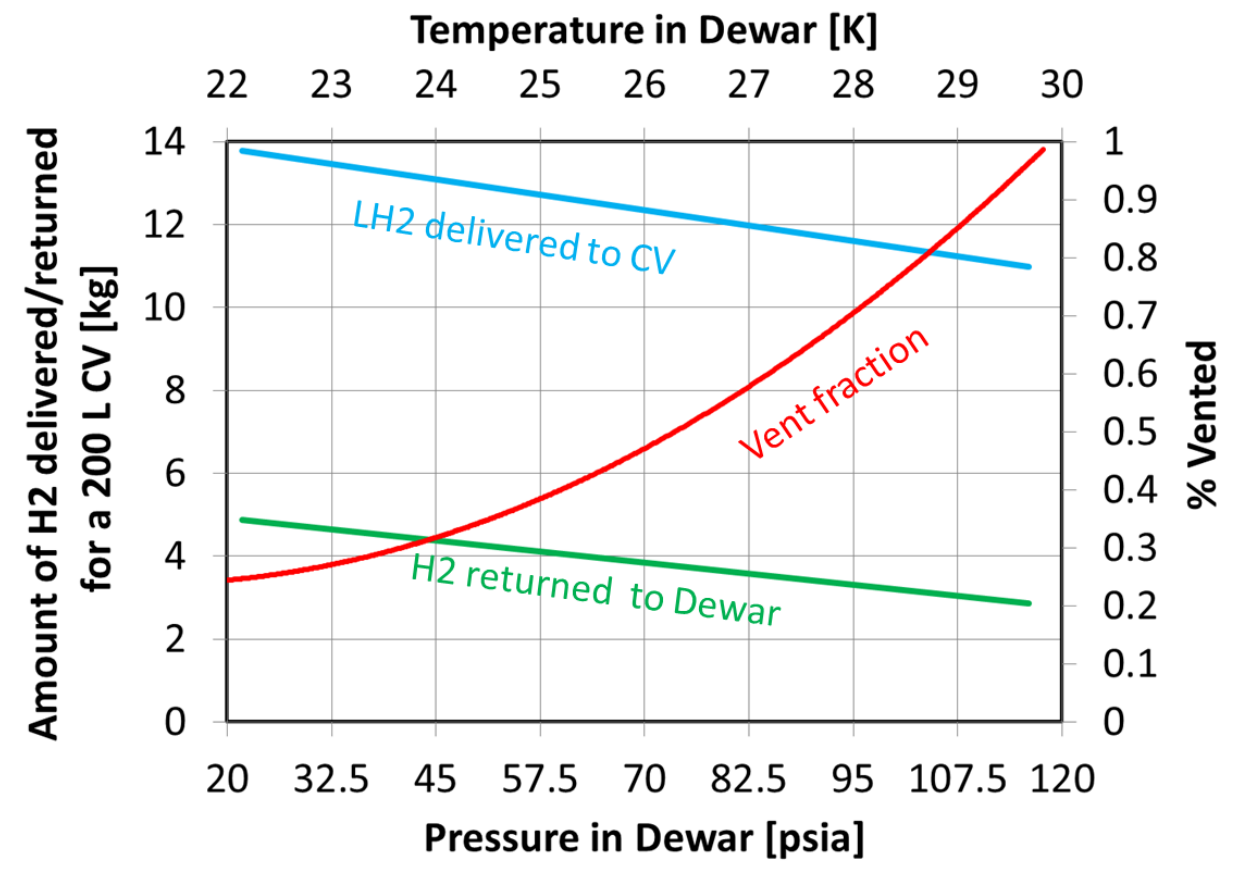

Figure 10. Influence of the vapor pressure (horizontal axis) on the amount of $\mathrm{H} 2$ delivered/returned for a $200 \mathrm{~L}$ insulated pressure vessels (left vertical axis) and corresponding vent fraction (right vertical axis). Bottom return mode.

The second recovery method utilizes some of the $\mathrm{H} 2$ that needs to be vented from a vessel in Step 4 to another vessel that was just filled with LH2 from the Dewar. The pressure between these two HPCHVs is allowed to equalize. As described earlier, this vent minimization step transfers some of the hydrogen earmarked for vent to a vessel recently filled with LH2. This step will increase the density in the vessel just filled with LH2 and consequently leads to a lower maximum temperature when the maximum pressure is achieved. 
To illustrate the advantages of including this step in the process, Figure 11 shows the pressure variations vs. the mass of $\mathrm{H} 2$ transferred for two vessels exchanging hydrogen in Step 4. One vessel is initially at $110 \mathrm{bar}, 118 \mathrm{~K}(21 \mathrm{~g} / \mathrm{L} \mathrm{H} 2$ density $)$ and it is assumed that it is at the minimum pressure threshold for dispensing to the vehicles. The $\mathrm{H} 2$ remaining in the vessel needs to be removed in order to decrease the pressure below the pressure of the Dewar. A second vessel, just finished filling with LH2 from the Dewar,is at 3 bar, $23 \mathrm{~K}(63 \mathrm{~g} / \mathrm{L} \mathrm{H} 2$ density). The $\mathrm{H} 2$ from the first vessel is transferred to the second vessel until no more flow can occur during a pressure equalization step. In this example, $1.2 \mathrm{~kg} \mathrm{H} 2$ are transferred, instead of being vented to atmosphere. Not only does this step reduce the amount of hydrogen wasted during the process, but Figure 11 also shows a density increase from 63 to $69 \mathrm{~g} / \mathrm{L}$ and maximum temperature decrease from $175.5 \mathrm{~K}$ to $145.5 \mathrm{~K}$ in the second vessel. As a result, the increase of usable $\mathrm{H} 2$ using this recovery method is, for this example, from $42 \mathrm{~g} / \mathrm{L}(=63-21 \mathrm{~g} / \mathrm{L})$ to $54 \mathrm{~g} / \mathrm{L}(=69-15$ $\mathrm{g} / \mathrm{L})$, a $28 \%$ gain.

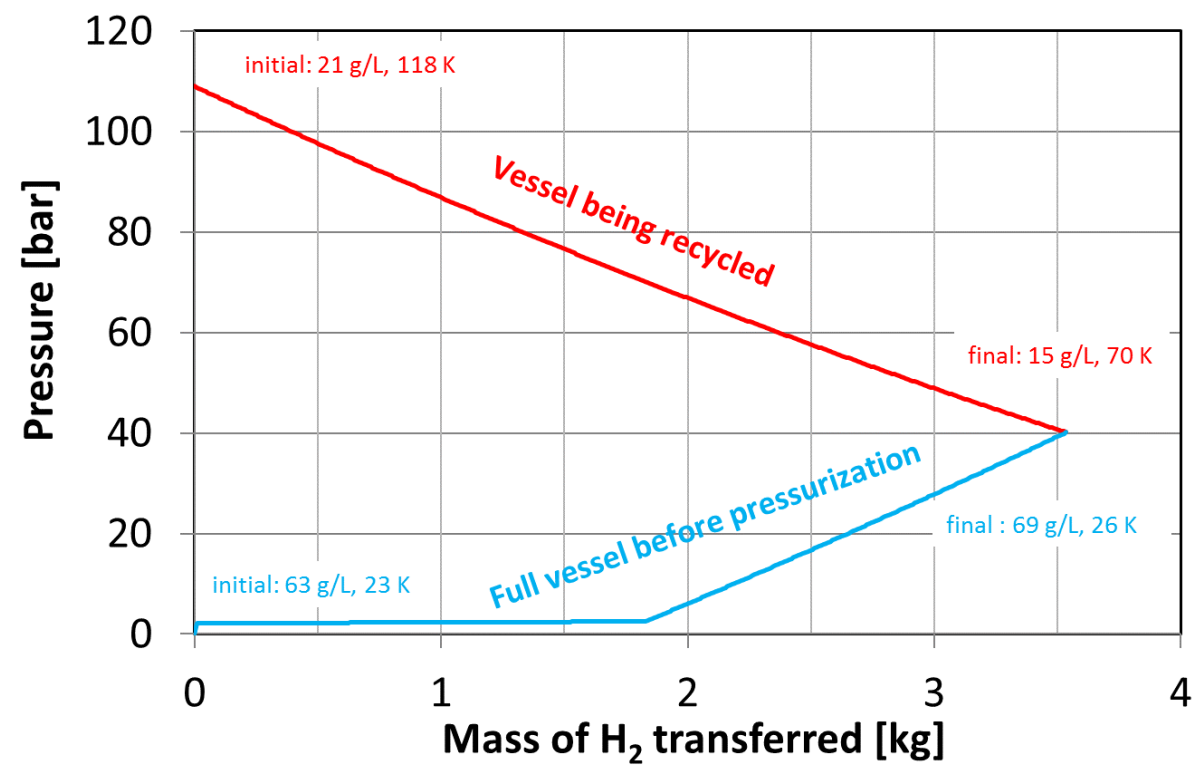

Figure 11. Pressure variations as a function of mass of $\mathrm{H} 2$ transferred in two pressure vessels: the first one is initially at 110 bar, $118 \mathrm{~K}(21 \mathrm{~g} / \mathrm{L} \mathrm{H} 2$ density) and it is assumed that it can not dispense $\mathrm{H} 2$ anymore thus needs to be recycled (red line); while the second vessel, initially at 3 bar, $23 \mathrm{~K}(63 \mathrm{~g} / \mathrm{L} \mathrm{H2}$ density) was just filled with LH2 and awaits pressurization (blue line). As $\mathrm{H} 2$ is transferred from the first to the second vessel, pressure difference decreases. This calculation also assumes a $200 \mathrm{~L}$ internal volume for the pressure vessels.

The third recovery method uses the $\mathrm{H} 2$ that is vented during a LH2 fill to pre-cool another vessel. Indeed, the $\mathrm{H} 2$ that is vaporized during the $\mathrm{LH} 2$ fill has a low temperature and could help in the cooling process. Figure 12 shows the variations of temperature and $\mathrm{H} 2$ masses during the LH2 fill, with and without the recovery method, continuous and dotted lines, respectively. The blue lines represent the temperature variation, the green lines the increasing amount of $\mathrm{H} 2$ in the vessel and the red lines the mass of $\mathrm{H} 2$ that is vented during the process, and recirculated into another vessel. Most of the venting is used to cool down the vessel (here, 4 to $4.5 \mathrm{~kg}$ ). Using the recovery method enables to lower the initial temperature in the vessel from 86 to $79 \mathrm{~K}$, saving $0.5 \mathrm{~kg}$ of $\mathrm{H} 2$ out of a $13.4 \mathrm{~kg} \mathrm{H} 2$ fill; a $3 \%$ saving. Figure 12 illustrates the major challenge of the overall thermal compression design: a significant quantity of LH2 needs to be used to remove the energy that has been accumulating in the pressure vessel wall and decrease the vessel wall temperature to LH2 temperatures. Once the LH2 touches the vessel wall, it becomes vapor (low density, low pressure, medium temperatures) with very little use at the station. One of the most realistic solution to capture that boil-off is to use a compressor, but this would defeat the purpose of a "compressor-less" station; nevertheless, such a solution is evaluated in the last section of this document. 


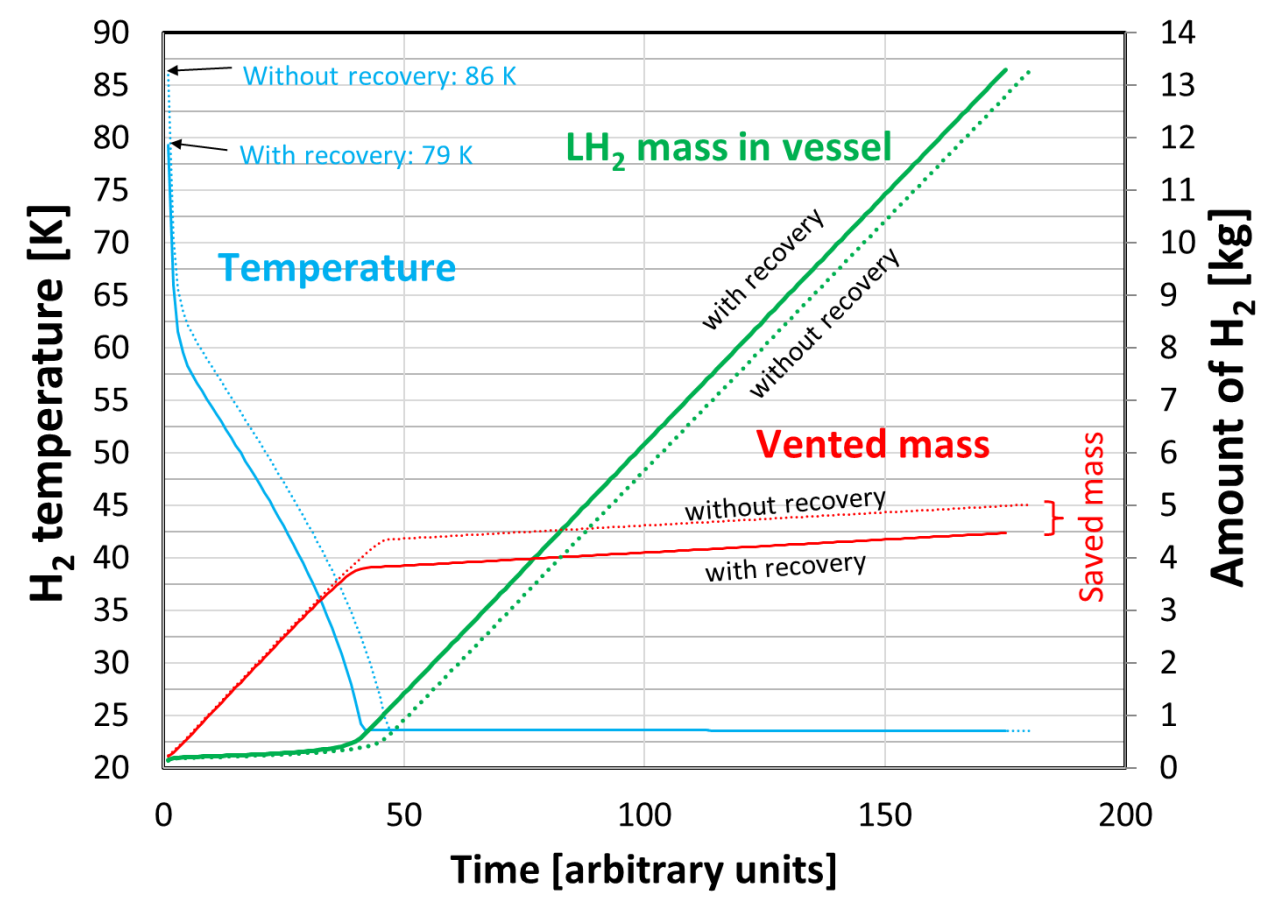

Figure 12. Temperature and mass variations with and without the recovery method during the LH2 fill (continuous line: with recovery, dotted line: without recovery).

Once the thermodynamic models, each in excess of 2000 lines of code, were completed, they were exercised to try to optimize the station design. The goal of these runs was to try to identify the parameter or combination of parameters that would result in a station design that would minimize the delivered hydrogen cost to the vehicle. The following observations could be made. First, it appears that the thermal compression offers better economic when using a cascade of many vessels of small volume, as opposed to fewer vessels of large volume. Second, a time window of at least 72 hours of model time is necessary to make sure that the permanent regime of the station is well captured. Third, given the flow rates of the return $\mathrm{H} 2$ flow to the Dewar, bottom recirculation should be used (e.g. thermosyphon). Under those working conditions, the pressure in the Dewar appears to be the most sensitive parameter that controls overall losses. Still under those conditions, transfer recirculation (warm empty vessel to full cold low pressure vessel) is a more effective way to reduce losses, as compared to pre-cooling. The station design and subsequent economic analysis presented in the following sections stem from the results and analysis of these thermodynamic modelling runs.

\subsection{HIGH PRESSURE CRYOGENIC HYDROGEN VESSELS}

The pressure vessels of the cryogenic cascade need to be designed according to their duty cycles in order to provide the most ecnomic solution. The following presents the design analysis for the High Pressure Cryogenic Hydrogen Vessels (HPCHV) that would meet the expected duty cycles. Compared to conventional cryogenic vessels, HPCHV must sustain a combination of significantly higher pressure (up to $900 \mathrm{MPa}$ ), a much wider temperature range (20K to ambient temperature) and a high number of pressure cycles (up to 45,000 cycles).

\subsubsection{Requirements of the HPCHV for Thermal Compression Application}

Pressure vessel design is a major element for the concept development and cost analysis for thermal compression concept. The pressure vessels suitable for this application will need to meet the requirements 
for the combined thermal and pressure cycling of the thermal compression process. A baseline HPCHV requirement includes the follwoing operation pressure and temperature window adopted from Figure 7:

$\{100 \mathrm{~K}, 3 \mathrm{bar}\} \rightarrow\{20 \mathrm{~K}, 1 \mathrm{bar}\} \rightarrow\{160 \mathrm{~K}, 900 \mathrm{bar}\} \rightarrow\{100 \mathrm{~K}, 150 \mathrm{bar}\} \rightarrow\{100 \mathrm{~K}, 3 \mathrm{bar}\} \quad 15-30$ cycles/day

The cycle life target is 15,000 cycles for 10 years, 30,000 cycles for 20 years or 45,000 cycles for 30 years. The baseline HPCHV size was determined to be $200 \mathrm{~L}$, which contains $13 \mathrm{~kg} \mathrm{H}_{2}$ at 900 bar at $160 \mathrm{~K}$.

The cryogenic temperature of HPCHV poses a major limit on cost-effective materials suitable for this application. ASME BVP code, for examle, Sec. VIII Div 1 Part ULT (2015 Ed), lists the following typical classes of materials for cryogenic use:

- Aluminum Alloy

- Stainless Steel

- $\quad 9 \%$ Ni Steel

These materials are generally much more expensive than carbon and low alloy steels for pressure vessel operated at room temperature. Because these materials are not a common as the low alloy steels there is often a learning curve when working with them, which can also increase construction costs. However, since cryogenic hydrogen applications as well as other cryogenic applications are becoming more prevalent, there is opportunity to discover lower cost materials. For example, one of ORNL's industry collaborators recently developed a cost-effective high $\mathrm{Mn}$ steel and it has the potential for cryogenic applications (including LNG ocean tanks). This steel was also considered in this study. Information regarding the $9 \% \mathrm{Ni}$ steel was provided by a major US steelmaker who expressed strong interests to assist in the project. The cost of 9\% Ni steel was confirmed with additional information from this steelmaker.

Hydrogen compatibility is another major concern when selecting materials suitable for the thermal compression application. Stainless steel SS316, certain classes of Ni based alloys, and Al alloy generally show little $\mathrm{H}_{2}$ embrittlement; however, information and relevant data on hydrogen compatibility of $9 \% \mathrm{Ni}$ steel and the high Mn steel is very limited. These materials were kept in consideration for this project even though it was recognized that additional compatibility studies were required, that were outside the scope of this project. However, it is possible to use these materials with ORNL's Steel-ConcreteComposite-Vessel (SCCV) design concept which eliminates the hydrogen compatibility by design [10].

The design fatigue life of a HPCHV was another challenge, as it was about an order of magnitude higher than the life cycle of on-board cryogenic storage vessels. The requirement for a high design cycle life of 45,000 cycles for 30 years would severely limit the use of Al alloy as a potential HPCHV material because the fatigue life of $\mathrm{Al}$ alloy (even in air) is known to be limited. SS316 was chosen as the baseline material for HPCHV, with the low cost high Mn steel and 9\% Ni steel as alternative material options due to potential cost benefits.

Vessels for cryogenic application are typically Multi-Layer Vacuum Super Insulation (MLVSI) design. In this design, the inner vessel is designed to sustain the pressure loading under cryogenic temperatures. The inner vessel is inside the outer vessel (or jacket), and vacuum is maintained between the inner vessel and the outer jacket to provide insulation. This vacuum insulation layer minimizes the heat exchange between the vessel and the surrounding atmosphere to keep the inner vessel in the intended cryogenic temperature range. However, in the case of the HPCHV design, a certain amount of heat transfer into the vessels is desired to increase the vessel pressure. Insulation techniques with vacuum or with commercial insulation materials could be considered as methods to reduce vessel cost.

For HPCHV design, a list of different pressure vessel options was developed and then down-selected the most suitable option for thermal compression hydrogen stations. 


\subsubsection{Evaluation of Existing Vessels for Thermal Compression Application}

A preliminary survey of different types of vessels for thermal compression application was performed. The results are summarized in Table 1. Currently, there are commercially available pressure vessels for hydrogen storage; however, none of these vessels are designed to meet the unique requirements of the thermal compression cycle (extreme temperature variations and pressure cyclic loading to 45,000 cycles).

\section{Type I Vessels}

As mentioned previously, available ASME approved material for cryogenic application include Aluminum alloy, stainless steel, and $9 \% \mathrm{Ni}$ steel. These materials have known mechanical properties and the ASME code can be followed to design Type I vessels with these materials for the thermal compression application. However, preliminary analysis indicates that vessels with these three materials have considerable variations in the cost. Non-ASME materials were also considered in order to show how innovation in materials could reduce costs. Material properties and cost information for some of these proprietary materials were provided by ORNL's industry collaborators.

\section{Type II vessel}

The innovative Steel-Concrete-Composite-Vessel (SCCV) developed at ORNL has been validated and shown to reduce cost of stationary gaseous hydrogen storage [10]. The original SCCV design will require modification in order to apply it to the thermal compression process. The preliminary analysis indicates this design has potential to meet the cost target, cyclic life and thermal mass; however, this design will require more research. Items of concern that will require further investigation include the material compatibility of pre-stressed wires for cryogenic application and the effect of fatigue. Some of these issues are currently being investigated at ORNL.

\section{Type III Vessel}

Type III vessels comprising of an aluminum liner wrapped with carbon fibers have been used for onboard cryo-compressed hydrogen storage. However, as previously discussed, aluminum is a questionable material choice due to fatigue issues. In a recent experimental study [11], failure location of Type III vessel during cyclic fatigue testing occurred in the metallic liner, after a simulated $\sim 10,000$ refueling cycles. This poses a major technical challenge for Type III vessels with Al liners since the thermal compression station concept will require the endurance for much higher number of cycles. Finding methods of reducing the stresses (thus increasing the fatigue life) in the liner can be difficult, likely involving much thicker carbon fiber wrapping which will significantly increase the cost.

Another example of Type III vessels currently available came from Company W. Company W specializes in Type III vessel. Currently there are vessel sizes ranging from 90L to 313L but with lower pressure of 517bar. For vessel size of 313L, to assemble a modular configuration for larger capacity will result in total cost of about $\$ 950 / \mathrm{kg}$ of $\mathrm{H} 2$, including the vessels, valves, frames and other accessories. The vessels are certified under US DOT protocols for gas transport cylinders, and DOT traditionally limits the service life of composite cylinders to 15 years, and for the European market, it is approved for 20 year for the 500 bar, 230L cylinder under ISO 11119-2 design protocols. The number of cycles and loading conditions will need to be evaluated to check if this will be sufficient for the thermal compression. The unresolved issue is the service for cryogenic $\mathrm{H} 2$ and its service life for the extreme thermal cycles. This company has cryogenic hydrogen tanks but currently not with the higher pressure requirement. The required vessel for this application must be specially designed and then tested to demonstrate its integrity. 
Also, the cost of Type III vessels is known to be high due to the use of expensive carbon fiber wrapping. In terms of cost projections, available literature research data are usually projected based on mass production of 500,000 units or more, with some assumptions that would need more vetting or basis. For example, the assumption of cost reduction on certain major BOP components at $90 \%$ when the production rate scaled up to 500,000 unit. The biggest unknown factor for Type III vessels is the integrity of the vessels after 45,000 cycles of combined temperature and pressure loading. The major advantage or Type III vessels is likely its low thermal mass.

Due to the lack of existing Type III vessel designs capable of withstanding the thermal compression cycle, vessel designs with different liner material should be investigated.

Table 1. Survey of existing different types of inner vessel for thermal compression application

\begin{tabular}{|c|c|c|c|c|c|}
\hline Basic options & Material & $\begin{array}{l}\text { Cost } \\
\$ / \mathrm{kg} \mathrm{H} 2\end{array}$ & $\begin{array}{l}\text { Approx. } \\
\text { Weight*, lbs }\end{array}$ & $\begin{array}{l}\text { Approx. } \\
\text { Thermal } \\
\text { mass**, } \\
\mathrm{kJ} / \mathrm{C}\end{array}$ & Remarks \\
\hline \multirow{4}{*}{ Type I } & Aluminum alloy & High & 4,000 & 1500 & ASME code compliant \\
\hline & Stainless steel 304 & High & 5,000 & 1200 & ASME code compliant \\
\hline & Alternative steel & Low & 2,700 & 550 & $\begin{array}{l}\text { Material under ASME code } \\
\text { case consideration }\end{array}$ \\
\hline & $9 \%$ Ni. steel & High & 2,200 & 450 & ASME code compliant \\
\hline $\begin{array}{l}\text { SCCV (Type } \\
\text { II) }\end{array}$ & Flexible & $\begin{array}{l}\$ 600-800 \\
{[10]}\end{array}$ & $2,500-3500$ & 300 & $\begin{array}{l}\text { Design for cryogenic } \\
\text { applications need to be } \\
\text { refined/optimized }\end{array}$ \\
\hline \multirow{2}{*}{ Type III } & Aluminum/CF & High [12] & 400 & 250 & \multirow{2}{*}{$\begin{array}{l}\text { Durability for } 10^{5} \text { combined } \\
\text { pressure and temperature } \\
\text { loading cycles needs to be } \\
\text { investigated for cryogenic } \\
\text { applications [13] }\end{array}$} \\
\hline & $\begin{array}{l}\text { Aluminum/ } \\
\text { Glass fiber [14] }\end{array}$ & TBD & 400 & TBD & \\
\hline Type IV & Polymer liner/CF & $\begin{array}{l}\$ 560-1100 \\
@ 700 \mathrm{bar}^{\S} \\
{[15]}\end{array}$ & TBD & TBD & $\begin{array}{l}\text { Durability for } 10^{5} \text { combined } \\
\text { pressure and temperature } \\
\text { loading cycles has been } \\
\text { shown to be inadequate. }\end{array}$ \\
\hline
\end{tabular}

Note: *: based on a vessel with $200 \mathrm{~L}$ net volume

**:estimated for ambient temperature as a reference data point.

$\S$ : projected from mass production of 500,000 unit per year

\section{Type IV vessel}

Type IV vessels were briefly considered, but many design challenges eliminated this type of vessel from consideration. One Type IV vessel manufacture, Company H, claims their Type IV vessels have never been targeted the cryogenic application but they have demonstrated successful performance in cryogenic screening tests. Therefore, this type of vessel will have to be experimentally demonstrated and tested to establish reasonable design life margins. These challenges include:

- Cryogenic temperature cycles may cause a reduction in liner material properties that reduces the elastic and thermal properties of the liner material

- Thermal fatigue tolerance during the extreme temperature cycles

- Mechanical responses to accidental impact or failure mode for large amount of pressure cycles

- Issues associated with $\mathrm{H} 2$ permeation through the liner at cryogenic conditions. 


\section{$\underline{\text { Vessel Option Summary }}$}

The goal of this project was to identify the potential vessel options and the pending issues associated with each option for this thermal compression application. Table 2 summarizes the initial feasibility evaluation of different vessel options. It is noted that the options listed in Table 2 are based on vessels that can be manufactured today. Per our communications with different vendors, we also note that, although all have the potential, not all vessel options can meet all the requirements for thermal compression application in this project.

Table 2. Feasibility of existing vessels for thermal compression application

\begin{tabular}{|c|c|c|c|c|c|c|}
\hline Vessel Options & $\begin{array}{l}\text { Cryogenic } \\
20 \mathrm{~K} \text { to } \\
200 \mathrm{~K}\end{array}$ & $\begin{array}{l}\text { Pressure } \\
\text { 900bar }\end{array}$ & $\begin{array}{l}\text { Volume } \\
\text { (liter) }\end{array}$ & $\begin{array}{l}\text { Combined T-P } \\
60,000- \\
110,000 \text { cycle } \\
\text { life }\end{array}$ & Cost & Notes \\
\hline $\begin{array}{l}\text { Type I [16], [17], } \\
\text { [18] }\end{array}$ & Yes & Yes & $\begin{array}{l}\text { No practical } \\
\text { limit }\end{array}$ & $\begin{array}{l}\text { Yes, per } \\
\text { ASME BPV }\end{array}$ & TBD & $\begin{array}{l}\text { Testing under } \\
\text { combined T-P } \\
\text { cyclic loading } \\
\text { is needed. }\end{array}$ \\
\hline Type II & Feasible & Yes & $\begin{array}{l}\text { No practical } \\
\text { limit }\end{array}$ & $\begin{array}{l}\text { Yes, per } \\
\text { ASME BPV }\end{array}$ & $\begin{array}{l}\text { TBD, potentially } \\
\text { lower than Type I } \\
{[19]}\end{array}$ & $\begin{array}{l}\text { Wire wrapping } \\
\text { material need } \\
\text { to be identified } \\
\text { and tested }\end{array}$ \\
\hline Type III & Feasible & $\begin{array}{l}\text { Currently } \\
\text { available up to } \\
517 \text { bar }[20]\end{array}$ & $\begin{array}{l}90 \text { to } 313 \mathrm{~L} \\
\text { is available }\end{array}$ & No experience & $\begin{array}{l}\$ 950 / \mathrm{kg} \mathrm{H}_{2} @ 517 \\
\text { bar }\end{array}$ & $\begin{array}{l}\text { Liner failure } \\
\text { under cyclic } \\
\text { loading is a } \\
\text { critical limiting } \\
\text { factor }\end{array}$ \\
\hline Type IV & $\begin{array}{l}\text { Initial } \\
\text { feasibility }\end{array}$ & Yes [21] & $\begin{array}{l}254 \mathrm{~L} \text { is } \\
\text { available }\end{array}$ & No experience & TBD & $\begin{array}{l}\text { Possible } \\
\text { degradation of } \\
\text { liner at } \\
\text { cryogenic T } \\
\text { and combined } \\
\text { T-P cyclic } \\
\text { loading }\end{array}$ \\
\hline
\end{tabular}

In summary of the survey on existing vessels, the most feasible vessel option today is a Type I vessel. It can be designed per ASME BVP code design rules for volume, pressure and temperature range, as well as meeting the demanding 45,000 cyclic loading requirement for the thermal compression cascading scenario optimized in this project. Manufacturers are available to fabricate such vessels per specification and ASME code. Current commercially available Type IV vessels from reputable vessel manufacturer are not designed for the intended thermal compression application. A number of technical issues will need to be investigated. According to the manufacturer we contacted, "Type IV vessel will have to be experimentally demonstrated and tested to establish a reason design life margin for thermal compression application." Type III vessel is another likely option. Like Type IV vessel, the durability and fatigue life under the combined extreme thermal and mechanical cyclic loading of thermal compression cascading scenario would require some design changes and experimental testing. The failure of metallic liners of Type III vessel during fatigue cyclic testing is another technical challenge that must be solved before it can be used for thermal compression application. Type II vessel offers a design feasibility and may have considerable cost advantages. However, further studies are needed to determine high-strength wires suitable for cryogenic applications. 


\subsubsection{Design and Cost Analysis of HPCHVs for Thermal Compression Application}

In order to make a more accurate estimation on the cost of HPCHV, a detailed design of the vessels was required. The goal of the design was to determine the physical attributes (length, wall thickness, wrapping thickness) of the vessel so a material cost could be determined. The physical parameters also lead to a thermal mass input which was needed for the thermodynamic modeling as well as the overall size footprint for the station.

The design criteria for this study were based on ASME BVP Section VIII Division 3 for its static strength. Finite element method (FEM) was used for stress analysis. An example of the FEM model features are presented in Figure 13. Due to vessel symmetry a quarter axisymmetric model of the vessel was used. Fabrication techniques are considered to allow Type II with pre-stressing from wirewrapping for $\sim 50 / 50$ load sharing; and Type III with autofrettage to introduce compressive stresses in the liner. The effect of hydrostatic testing (autofrettage) at $125 \%$ design pressure on local residual stress was evaluated.

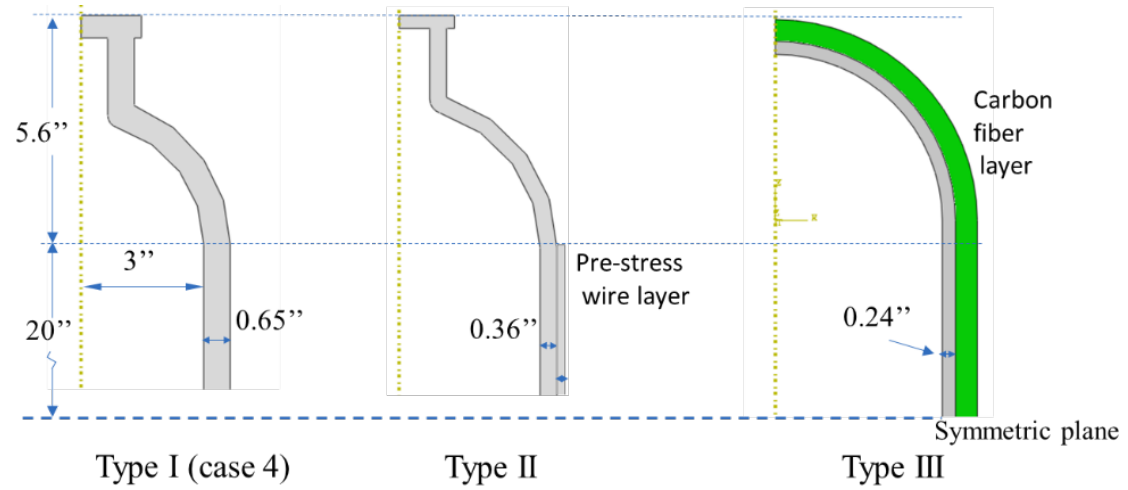

Figure 13 Examples of FEM model features

\subsubsection{Type I Vessel}

Under the thermal compression scenario, each vessel was designed with 200 liter water volume, subjected to 900 bar maximum pressure at $200 \mathrm{~K}$, and had a minimum cyclic life requirement of 45,000 cycles under the combined thermal and pressure cycles. The initial designs included vessels with 6 inch and 8 inch inner diameter. The vessel material was SS316 stainless steel chosen for its compatibility for both cryogenic and hydrogen service. A drawback of SS316 was its relative low design allowable stress. Means of increasing the design allowable such as cold work hardening are possible, but require experimental testing and validation. Responses from Type I pressure vessel manufacturers have been positive in terms of manufacturability of such a vessel, including the practical material limitations on vessel wall thickness. Fatigue life assessment per ASME code design rule confirmed the initial design would pass the 45,000 life cycle requirement.

Seamless vessel fabrication was considered for the Type 1 vessels in this study. The design procedure followed ASME BVP Sec VIII Div. 3 code with the following steps:

Step 1. Calculate/specify shell wall thickness based on static stress at maximum operation pressure, $900 \mathrm{bar}$

Step 2. Let head thickness equal shell thickness

Step 3. Confirm fatigue life based on KD-3 and the above wall thickness at internal pressure range of 900 bar to zero.

The static stress for SS316 is governed by general yielding. The stresses in the shell and the head are determined using FEM. The reference material SS316 is relatively expensive. Based on surveys with US 
vessel manufacturers and material suppliers, the cost of SS316 strongly depends on the thickness and other factors (such as plates, tube, surface finish etc). For thickness above 2 in, the cost of SS316 tubes is in the range of $\$ 5-6.5 / \mathrm{lb}$. For thickness that are more commonly available $(<0.8$ " for 6 " ID pipes/tubes), the cost of SS316 tubes is in the range of $\$ 2.25-3.5 / \mathrm{lb}$. As a first order cost projection, material cost of SS316 was scaled as a function of vessel wall thicknesses bounded by the above two quotes. The cost of the High Mn steel is about 50\% of SS316, and the cost of $9 \% \mathrm{Ni}$ is about $60 \% \mathrm{SS} 316$. Fabrication cost depends on a variety of factors including methods of manufacturing, capacity and capability of manufacturer, quantity of vessels ordered etc. The manufacturing cost was assumed to be $50 \%$ of the material cost, which is reasonable for the materials and manufacturing processes considered for HPCHVs.

A total of 4 cases were analyzed for Type 1 vessel baseline design with two diameters: 6 or 8 inch inner diameter. Table 3 summarizes the design parameters and the allowable cycles for these cases. Case I-1 represents the design of a Type 1 vessel with annealed SS316 using ASME requirement mechanical properties at room temperature. The results show that this design has allowable fatigue cycle life in excess of 1 million. The heavy wall thickness for this design is governed by the maximum design pressure of $900 \mathrm{bar}$ and therefore this design is expected to be expensive to fabricate.

Case I-2 design used mechanical properties at $160 \mathrm{~K}$ when the vessel experiences the highest internal pressure of 900bar. The increased strength of SS316 at low temperature reduces the design wall thickness. The allowable fatigue cycles are more than 580,000, and therefore, fatigue is not an issue for the thermal compression application of 30 years service for this design case.

Case I-3 represents a technically achievable design but beyond the ASME code. Taking advantage of work hardening of SS316 to further increase the yield strength allow a design with reduced wall thickness. The reduced wall thickness leads to a reduction in fabrication cost. It is estimated that 7 to $10 \%$ cold work on the vessel wall would increase the yield strength to $65 \mathrm{ksi}$. Literature data suggest small amount of cold work will not adversely affect the performance of SS316 in high pressure hydrogen, for certain SS316 with rich Ni. However, this technique would require additional testing and validation to confirm this literature data. The allowable cycles for case I-3 are 3-4 times greater than the required for 30 year service for the thermal compression application.

In order to reach the minimum wall thickness to meet the 45,000 cycles ( 30 year service), a hypothetical case I-4 was evaluated. The yield strength of the design material was increased to $83.5 \mathrm{ksi}$, which was much higher than what SS316 steel could technically achieve. The wall thicknesses are reduced to less than one inch for both cases. In this case, the wall thickness comforms with standard commercially available pipes and therefore the cost will be significantly reduced. However, this case assumed the material must have excellent fatigue resistance in hydrogen that is comparable to SS316. Note that the $9 \%$ $\mathrm{Ni}$ steel can meet the required static strength for Case I-4, although its performance in high pressure $\mathrm{H} 2$ environment needs further investigation.

Table 3. Type 1 Vessel Design using SS316

\begin{tabular}{|l|l|l|l|l|l|l|}
\hline Cases & $\begin{array}{l}\text { ID, } \\
\text { in }\end{array}$ & $\begin{array}{l}\text { Wall } \\
\text { thickness, } \\
\text { in }\end{array}$ & $\begin{array}{l}\text { Yield } \\
\text { strength, } \\
\text { ksi }\end{array}$ & $\begin{array}{l}\text { Allowable } \\
\text { cycles in the } \\
\text { shell }\end{array}$ & $\begin{array}{l}\text { Allowable } \\
\text { cycles of the } \\
\text { nozzle on the } \\
\text { head }\end{array}$ & Comments \\
\cline { 1 - 5 } Case I-1 & 6 & 2.2 & 30 & $>>1$ million & $>1$ million & $\begin{array}{l}\text { Yield strength is based on ASME minimum } \\
\text { requirement at RT }\end{array}$ \\
\cline { 2 - 3 } & 8 & 2.9 & & $>>1$ million & $>1$ million & Yield strength converted from design allowable \\
in Sec. VIII Div.1 table ULT-23 for 160K.
\end{tabular}




\begin{tabular}{|c|c|c|c|c|c|c|}
\hline \multirow[t]{2}{*}{ Case I-3 } & 6 & 0.9 & \multirow[t]{2}{*}{65} & 252,777 & 159,702 & \multirow{2}{*}{$\begin{array}{l}\text { Yield strength is based on } 7 \sim 10 \% \text { cold work on } \\
\text { the vessel wall to increase the yield strength to } \\
\text { yield strength to } 65 \mathrm{ksi} \text {, }\end{array}$} \\
\hline & 8 & 1.14 & & 200,845 & 132,206 & \\
\hline \multirow[t]{2}{*}{ Case I-4 } & 6 & 0.65 & \multirow[t]{2}{*}{83.5} & 59,900 & 46,033 & \multirow{2}{*}{$\begin{array}{l}\text { a hypothetical consideration for the minimum } \\
\text { wall thickness to meet } 45,000 \text { cycles }- \text { the } \\
\text { feasibility of SS } 316 \text { (or other materials) to meet } \\
\text { such property requirement needs further } \\
\text { investigation }\end{array}$} \\
\hline & 8 & 0.875 & & 62,529 & 47,851 & \\
\hline
\end{tabular}

The stresses in the shell and the head are determined using FEM, and the stress ranges from FEM are used to calculate and confirm the projected fatigue life. The FEM model for case I-4 is shown below in Figure 14 as an example. The stresses of a nozzle area are also considered. Per ASME code, fatigue analysis used a stress concentration factor of 2 for the nozzel region. Note that the details of the nozzle configuration will greatly affect the stress concentration. This aspect was not considered at this concept level assessment and detailed engineering analysis will be necessary in the future.

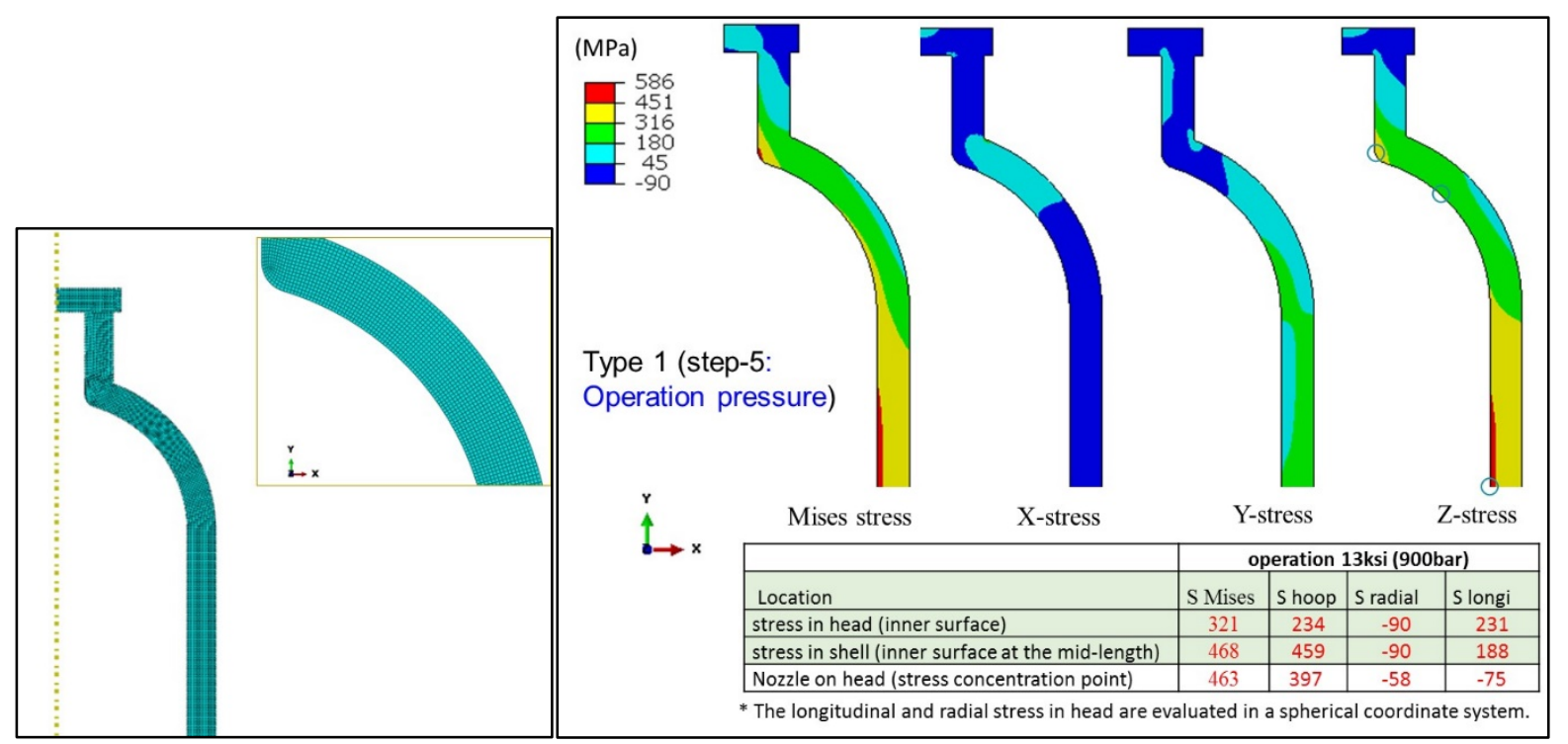

Figure 14. FEM mesh and the stresses at 900bar and $160 \mathrm{~K}$ for case I-4

The use of $\mathrm{Al}$ alloys and $9 \% \mathrm{Ni}$ steel for thermal compression vessel were also evaluated, both of which are ASME code accepted materials for cryogenic applications. However, as stated earlier, Al alloy has much lower fatigue life limit per ASME code design rule. The use of AL alloy was thus deemed to be impractical and would not evaluated further in this project for Type I design. $9 \% \mathrm{Ni}$ steel offers much higher allowable design stress, but its compatibility with $\mathrm{H} 2$ has yet to be investigated. The compatibility issue can be eliminated by use of an inner liner compatible with H2, a technique from ORNL's SteelConcrete-Composite-Vessel (SCCV) concept. This design option may be a path to lower cost vessels; however, such design options would require more detailed analysis and manufacturability investigation, which was beyond the scope of this project.

A number of inquiries were sent to vessel fabricators to get a cost estimation for this Type 1 design. The quotes showed that the cost of a vessel for 2-in wall thickness with 8 -in ID is about $\$ 4,400 / \mathrm{kg}$ of $\mathrm{H}_{2}$ stored using SS316. This cost number is the basis of the cost estimation for the above 4 cases studied. The overall cost estimation for Type I vessels and the assumptions are summarized in Table 4 . The total cost of the vessel consists of material cost and the fabrication cost. For this initial cost estimation, the fabrication cost is estimated to be $50 \%$ of the total material cost. Case I-1 vessel is assumed to have the 
same unit cost as what was quoted for the 8 inch ID with 2 inch wall thickness vessel. Case I-2 has $15 \%$ of reduced material cost over case 1 due to the reduced wall thickness. Case I-3 assumed $50 \%$ more in unit material cost over standard pipes due to the thicker wall. It can be seen that the projected cost is between $\$ 950-2400 / \mathrm{kg} \mathrm{H} 2$ at 900 bar for case I-2 and I-3. To further lower the cost, a potential candidate material, high $\mathrm{Mn}$ steel, is considered in case I-3Mn. This steel has mechanical properties comparable to case I-3 and the projected cost of the vessel made of high Mn steel is about $\$ 400-500 / \mathrm{kg}$ of H2 stored at 900 bar. Cases I-4Mn and I-4Ni use the concept of H2 permeation barrier in ORNL SCCV design to mitigate the hydrogen effect, so they are technically achievable now. The additional cost of mitigating $\mathrm{H} 2$ effect through design for these two cases were also adjusted accordingly.

Table 4 Overall cost estimates and underlining assumptions for Type 1 HPCHVs

\begin{tabular}{|c|c|c|c|c|c|}
\hline Case & Vessel material & $\begin{array}{l}\text { Yield strength of the } \\
\text { inner vessel, ksi }\end{array}$ & $\begin{array}{l}\text { Thickness } \\
\text { of } 6 " \text { ID, in }\end{array}$ & $\begin{array}{l}\text { Material Cost of the } \\
\text { vessel, \$/lb }\end{array}$ & $\begin{array}{c}\text { Projected } \\
\text { vessel cost, } \\
\$ / \mathrm{Kg} \mathrm{H} 2\end{array}$ \\
\hline $\mathrm{I}-1$ & SS316 & $\begin{array}{l}30 \text { (ASME min RT } \\
\text { prop) }\end{array}$ & 2.2 & $6.5^{*}$ & 5,400 \\
\hline $\mathrm{I}-2$ & SS316 & $\begin{array}{c}46 \text { (ASME min. } \\
\text { @ } 160 \mathrm{k})\end{array}$ & 1.28 & $5.53 *$ & 2,400 \\
\hline $\mathrm{I}-3$ & SS316 & 65 (coldwork@160k) & 0.9 & $3.4 * *$ & 950 \\
\hline $\mathrm{I}-3 \mathrm{Mn}$ & Hi Mn steel & 65 & 0.9 & $1.7^{\S}$ & $400-500$ \\
\hline $\mathrm{I}-3 \mathrm{Ni}$ & $9 \% \mathrm{Ni}$ steel & 83.5 & 0.65 & $1.5^{\S}$ & 300 \\
\hline $\mathrm{I}-4 \mathrm{Mn}$ & $\begin{array}{l}\text { Hi Mn steel, } \\
\text { SS316 liner }\end{array}$ & 65 & 0.9 & $1.7^{\S} / 2.25^{* * *}$ & $500-550$ \\
\hline $\mathrm{I}-4 \mathrm{Ni}$ & $\begin{array}{l}9 \% \text { Ni steel, } \\
\text { SS316 liner }\end{array}$ & 83.5 & 0.65 & $1.5^{\S /} 2.25^{* * *}$ & 400 \\
\hline
\end{tabular}

*Based on fabricator quote for 8in ID/2in wall thickness vessel

** assume $50 \%$ cost increase due to thicker wall than standard pipe for case 3

*** based on the price quote for commercially available standard pipes, consistent with PNNL SS316 material cost

$\S$ based on communication with ORNL's industrial partner

\subsubsection{Type II Vessel}

Following the concept of ORNL's SCCV design, a Type II vessel can be developed by pre-stressed wire wrapping a Type I vessel which has half of shell wall thickness when compared to the standard Type I vessel design. The overall cost estimation for Type II vessels are consistent with the analysis on Type I vessel. Such Type II vessel generally has cost advantage over the standard Type I vessel design as the reduced wall thickness results in lower raw material cost. However, determining suitable high-strength wire, such as SA648, which is cost-effective but also suitable for cryogenic temperature would require 
additional testing and validation. The results for Type II vessel designs are summarized in Table 5. The Type II designs appeared to be cost-effective, with projected cost in the range of $\$ 290-550 / \mathrm{kg} \mathrm{H} 2$.

Table 5 Overall cost estimates and underlining assumptions for Type II vessel

\begin{tabular}{|c|c|c|c|c|c|c|c|}
\hline Cases & $\begin{array}{c}\text { Inner vessel } \\
\text { material }\end{array}$ & $\begin{array}{l}\text { Inner vessel } \\
\text { thickness, in }\end{array}$ & $\begin{array}{c}\text { Yield } \\
\text { strength of } \\
\text { the inner } \\
\text { vessel } \\
\text { material, ksi } \\
(@ 160 \mathrm{~K})\end{array}$ & $\begin{array}{c}\text { Unit Cost of } \\
\text { the inner } \\
\text { vessel } \\
\text { material, } \\
\$ / \mathrm{lb}\end{array}$ & $\begin{array}{l}\text { Wrapping } \\
\text { material }\end{array}$ & $\begin{array}{l}\text { Unit material } \\
\text { Cost of the } \\
\text { wrapping } \\
\text { material } \\
\$ /{ }^{* *}\end{array}$ & $\begin{array}{c}\text { Projected } \\
\text { vessel cost, } \\
\$ / \mathrm{Kg} \mathrm{H} 2 \\
\text { stored }\end{array}$ \\
\hline II-2A & SS316 & 0.682 & $\begin{array}{c}46 \text { (ASME } \\
\text { min.) }\end{array}$ & $2.25 *$ & SS316 wire & 3.25 & 700 \\
\hline II-3A & SS316 & 0.468 & $\begin{array}{l}65(7 \sim 10 \% \\
\text { cold work) }\end{array}$ & $2.25 *$ & SS316 wire & 3.25 & 550 \\
\hline II-4A-Mn ${ }^{\$}$ & $\begin{array}{c}\text { High Mn } \\
\text { steel } \\
\text { (ORNL } \\
\text { SCCV } \\
\text { Design) } \\
\end{array}$ & 0.468 & 65 & $1.7^{*}$ & SS316 wire & 3.25 & 550 \\
\hline $\mathrm{II}-4 \mathrm{~A}-\mathrm{Ni}{ }^{\$}$ & $\begin{array}{c}9 \% \text { Ni steel } \\
\text { (ORNL } \\
\text { SCCV } \\
\text { Design) }\end{array}$ & 0.4 & 83.5 & 1.5 & SS316 wire & 3.25 & 450 \\
\hline II-2B & SS316 & 0.682 & $\begin{array}{l}46 \text { ASME } \\
\text { min. }\end{array}$ & $2.25 *$ & SA648 & 0.59 & 510 \\
\hline II-3B & SS316 & 0.468 & $\begin{array}{l}65(7 \sim 10 \% \\
\text { cold work) }\end{array}$ & $2.25 *$ & SA648 & 0.59 & 350 \\
\hline II-4B-Mn & $\begin{array}{c}\text { High Mn } \\
\text { steel } \\
\text { (ORNL } \\
\text { SCCV) } \\
\end{array}$ & 0.468 & 65 & 1.7 & SA648 & 0.59 & 370 \\
\hline II-4B & $\begin{array}{c}\% \text { Ni steel } \\
\text { (ORNL } \\
\text { SCCV) }\end{array}$ & 0.4 & 83.5 & 1.35 & SA648 & 0.59 & 290 \\
\hline
\end{tabular}

*consistent with Type 1 vessel cost and assumptions

** based on quotes on commercially available cold draw high strength SS316 wire

$\$$ ORNL SCCV design mitigate the Hydrogen embrittlement effect, but increase the cost by $10-15 \%$. The fatigue life requires further study.

\subsubsection{Type III Vessel}

The reference design for Type III vessel used aluminum alloy 6061-T6 liner, which is commercially available for on-board hydrogen storage with $\sim 10,000$ fatigue life at a lower design pressure [11]. The basics of Type III reference design was taken from Ref 13 . The aluminum liner thickness was $6 \mathrm{~mm}$. The Carbon Fiber (CF) wall thickness was selected from burst test analysis (analytical). The stresses in the $\mathrm{CF}$ and liner under burst test condition were evaluated by FEM. The final cost numbers were adjusted to reflect thicker wall required for achieving the 45,000 fatigue cycles, and the possibility of replacing aluminum liner with SS316.

The FEM analysis procedure is listed below:

- Simulating the Burst test to confirm static design

- $\mathrm{t}=0$, Initial condition: $\mathrm{Temp}=300 \mathrm{~K}, \mathrm{P}=0$

- Step $1(\mathrm{t}=0-1)$ : Autofrettage test at $300 \mathrm{~K}$.

- Autofrettage pressure is 1.25 (or 1.5) times of operation pressure Po. (Max autofrettage P) 
- Step 1A: linearly increase pressure to Autofrettage pressure at $\mathrm{t}=0.5$

- Step 1B: linear decrease pressure to zero at $\mathrm{t}=1.0$

- Step 2 ( $\mathrm{t}=1.0-3.0)$ : cyclic loading to Po $(90 \mathrm{MPa})$ at $300 \mathrm{~K}$ to determine plastic deformation

- Step 2A: linearly increase pressure to $90 \mathrm{MPa}$ at $\mathrm{t}=1.5$

- Step 2B: linear decrease pressure to zero at $\mathrm{t}=2.0$

- Step 2C: linearly increase pressure to $90 \mathrm{MPa}$ at $\mathrm{t}=2.5$

- Step 2D: linear decrease pressure to zero at $\mathrm{t}=3.0$

- Step $3(\mathrm{t}=3.0-4.0)$ : reduce temperature determine stresses due to CTE mismatch

- Step 3A: reduce $\mathrm{T}$ to $160 \mathrm{~K}(\mathrm{P}=0)$ at $\mathrm{t}=3.5$

- Step 3B: reduce $\mathrm{T}$ to $20 \mathrm{~K}(\mathrm{P}=0)$ at $\mathrm{t}=4.0$

- Step 4 ( $\mathrm{t}=4.0-6.0)$ : simulate cyclic cryogenic operation between $(20 \mathrm{~K}, 0 \mathrm{MPa})$ and $(160 \mathrm{~K}, 90 \mathrm{MPa})$

- Step 4A: increase $\mathrm{T}$ to $160 \mathrm{~K}$ and $\mathrm{P}$ to $90 \mathrm{MPa}$

- Step 4B: reduce $\mathrm{T}$ to $20 \mathrm{~K}$ and $\mathrm{P}$ to 0

- Step 4C: increase $\mathrm{T}$ to $160 \mathrm{~K}$ and $\mathrm{P}$ to $90 \mathrm{MPa}$

- Step 4D: reduce $\mathrm{T}$ to $20 \mathrm{~K}$ and $\mathrm{P}$ to 0

Figure 15 shows an example of the stresses in the aluminum liner at step 2 and step 4 calculated through FEM. The stresses are used for calculation of the fatigue life. If the fatigue design does not reach 45,000 cycles, the wall thickness of the CF was then increased to reduce the stresses in the liner. Similar process was also performed using SS316 liner material.

From the FEM analysis, it was determined that the thickness of CF (2550MPa ultimate tensile strength and $60 \%$ fiber volume) would be $11 \mathrm{~mm}$ to sustain a burst pressure (2.25 times of design presssure of $900 \mathrm{MPa}$ ). Under such static loading condition, the hoop stress in the aluminium liner would reach its ASME static design allowable of $241 \mathrm{MPa}$ (35ksi). To reach the 45,000 design cycle, the stresses in the aluminum liner would need to be reduced to $53 \mathrm{MPa}(7.74 \mathrm{ksi})$. This requires an increase in CF thickess of $55 \mathrm{~mm}$.
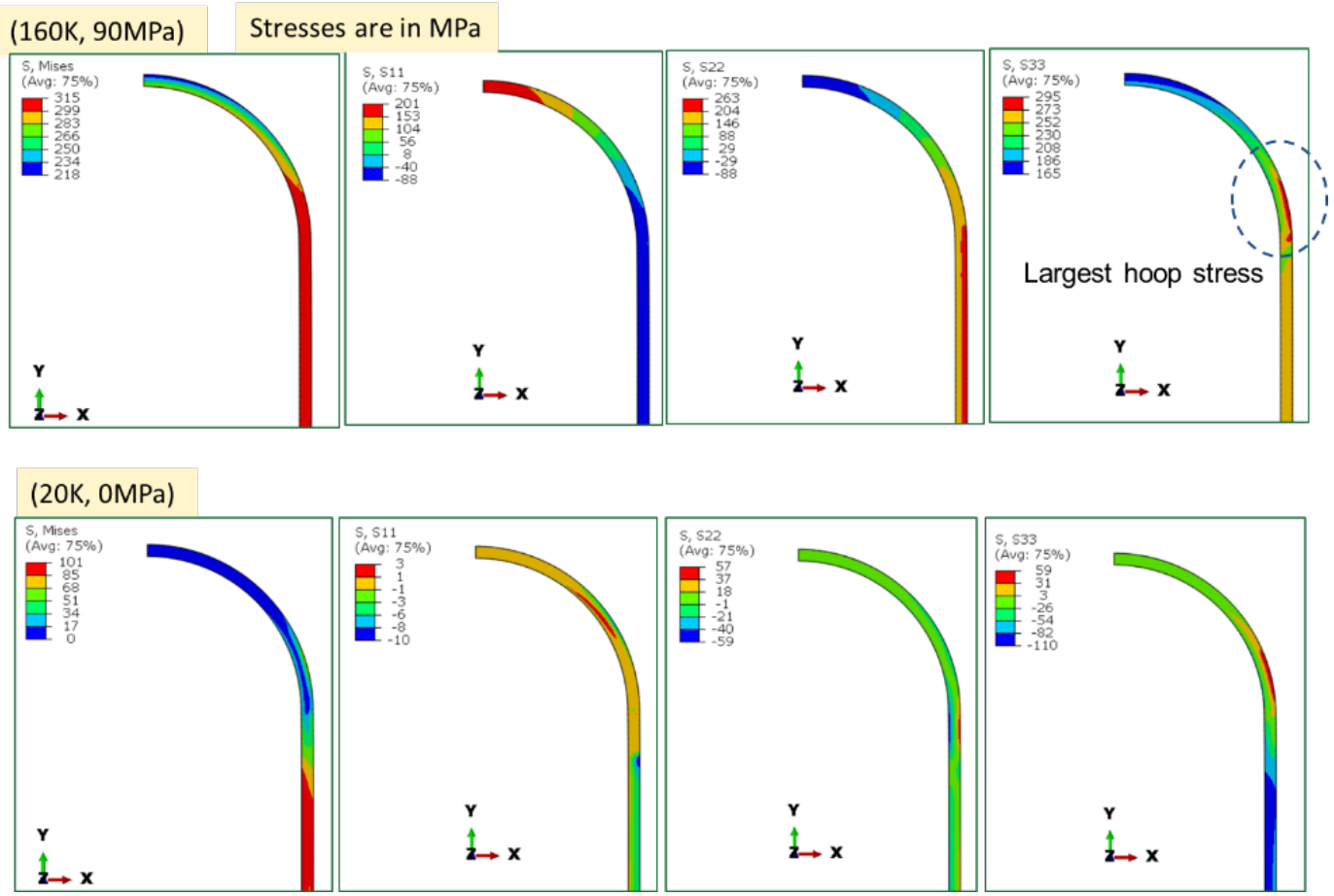

Figure 15. Stresses in the Aluminum liner after autofrettage at 1.25X operation pressure. 
The thermal expansion mismatch causes separation of liner and CF which may be another major hurdle to reach 45,000 cycles. Alternative SS316 liner for Type III HPCHV might be a potential solution.

However, separation of liner and $\mathrm{CF}$ in the head region may result in reduced fatigue life. This aspect was not included in the current fatigue calculation and cost projection. The extent of separation or remedies to eliminate the separation will be dependent upon the specific details of vessel head design.

Cost projections for a type III pressure vessel with an Aluminum liner for an on-board vehicle application have been published in (13): assuming large volume production, a 272 bar pressure rating (2.25 safety factor), and a $10.4 \mathrm{~kg} \mathrm{H}_{2}$ capacity; it was shown that the composite and the liner (including fittings) would cost $\$ 985$ and $\$ 542$, respectively. Our thermal compression design differs from that design for the three following reasons: the pressure rating is significantly larger (900 vs. 272 bar $)$, the production volume will be lower, and the duty cycle will be more strenous (45,000 vs. 10,000 cycles). As a result, the baseline cost projection should be modified as follows: multiply composite cost by a factor of $3.3(=900 / 272)$ to account for extra composite to withstand the pressure, add $\$ 150 / \mathrm{kg} \mathrm{H} 2$ to account for lower production volume, and multiply composite cost by a factor of 5 to account for the increased cycle life requirements. The new cost projection for a 900 bar type III pressure vessel with an Al liner for thermal compression then becomes: $(\$ 985 \times 3.3 \times 5+\$ 150 \times 10.4+\$ 542) / 10.4=\$ 1759 / \mathrm{kg} \mathrm{H} 2$.

A similar method is used to estimate cost projections for type III pressure vessel with a SS316 liner, except that the baseline liner cost is estimated to be $\$ 150 / \mathrm{kg} \mathrm{H} 2$ (see type I cost projections, above) and that the multiplying factor for additional carbon fiber to account for increased fatigue is only 1.2 (vs. 5 for Al) since SS316 has much higher fatigue life. The resulting cost projection for a 900 bar type III pressure vessel with a SS316 liner for thermal compression is: $(\$ 985 \times 3.3 \times 1.2+\$ 150 \times 10.4+\$ 150 \times 10.4) / 10.4$ $=\$ 675 / \mathrm{kg} \mathrm{H} 2$.

\subsubsection{Summary on HPCHV study for Thermal Compression Application}

There are no existing vessel designs for hydrogen storage that can be directly adopted for the thermal compression process. Type I vessel can be designed and constructed per ASME for this application. Using SS316 as baseline design, the vessel design is limited by static stress. Due to excellent fatigue strength of SS316, the design fatigue cycles for Case I-2 and Case I-3 are 3x to 10x higher than the design life. The projected cost of these SS316 vessels is between $\$ 950-2500 / \mathrm{kg} \mathrm{H} 2$ at 900 bar. By utilizing ORNL's hydrogen permeation barrier approach, lower cost and/or higher strength materials such as high Mn steel or $9 \% \mathrm{Ni}$ steel can be used to further reduce the projected Type 1 vessel cost to $\$ 400-500 / \mathrm{kg} \mathrm{H} 2$.

Type II vessel designs was most cost-effective, with projected cost in the range of \$290-550/kg H2. Reduced wall thickness resulted in lower raw material cost. High-strength wire is also cost effective but requires further evaluation for cryogenic application. ORNL's SCCV approach can be applied in the Type II designs to solve hydrogen compatibility issues if cost-effective high $\mathrm{Mn}$ steel or $9 \% \mathrm{Ni}$ steel is used for the inner vessel.

Today's existing Type III vessel with Al liner and CF wrapping will have difficulty achieving the 45,000 design cycle criteria. As much as 4-5 times more CF wrapping will be needed to reduce the stress range in Al liner for sufficient fatigue life. The cost of Type III vessel with Aluminum liner cost about $\$ 1800 / \mathrm{kg}$ of $\mathrm{H} 2$; however, it is possible to reduce the cost to $\$ 675 / \mathrm{kg} \mathrm{H} 2$ if the liner is replaced with SS316.

Table 6 provides a summary of the vessels investigated during this study. Type III vessel designs are higher in cost due to increased amount of carbon fiber used in construction; however, the Type III vessels do have advantages in the thermal compression application because of their lower thermal mass

Table 6 Summary of potential HPCHV design options for use in the thermal compression station. Numbers are given here for a $200 \mathrm{~L}$ inner volume, 6 in. inner diameter and 900 bar rated pressure vessel. (Table will need to be updated). 


\begin{tabular}{|c|c|c|c|c|c|c|c|c|c|c|c|c|c|}
\hline $\begin{array}{l}\text { Vessel } \\
\text { Type }\end{array}$ & Cases & $\begin{array}{l}\text { ID, } \\
\text { in }\end{array}$ & $\begin{array}{c}\text { Inner } \\
\text { vessol t } \\
\text { in }\end{array}$ & $\begin{array}{c}\text { base inner } \\
\text { vessel } \\
\text { weight, lbs }\end{array}$ & $\begin{array}{c}\text { Inner vessel } \\
\text { material }\end{array}$ & \begin{tabular}{|c|}
$\mathrm{H} 2$ \\
barrier \\
/liner \\
\end{tabular} & \begin{tabular}{|c|}
$\mathrm{H} 2$ \\
barrier/liner \\
weight, lbs
\end{tabular} & $\begin{array}{l}\text { wrapping } \\
\text { material }\end{array}$ & $\begin{array}{c}\text { wrapping } \\
\text { material } \\
\text { thickness, in }\end{array}$ & $\begin{array}{c}\text { wrapping } \\
\text { material } \\
\text { weight, lbs }\end{array}$ & $\begin{array}{c}\text { total weight } \\
\text { of the vessel, } \\
\text { lbs }\end{array}$ & & $\begin{array}{l}\text { oject } \\
\text { cost, } \\
\mathrm{kg} \mathrm{H} 2\end{array}$ \\
\hline \multirow{6}{*}{1} & $1-2$ & 6 & 1.28 & 3,680 & SS316 & none & 0.0 & none & none & none & 3,680 & $\$$ & 2,400 \\
\hline & $1-3$ & 6 & 0.9 & 2,450 & SS316 & none & 0.0 & none & none & none & 2,450 & $\$$ & 950 \\
\hline & $\mathrm{I}-3 \mathrm{Mn}$ & 6 & 0.9 & 1,705 & High $M n$ steel & none & 0.0 & none & none & none & 1,705 & 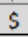 & 500 \\
\hline & $\mathrm{I}-3 \mathrm{NI}$ & 6 & 0.65 & 2,450 & 9NI steel & none & 0.0 & none & none & none & 2,450 & $\$$ & 300 \\
\hline & $1-4 M n$ & 5.76 & 0.9 & 2,450 & Mn Steel & SS316 & 273 & none & none & none & 2,724 & $\$$ & 550 \\
\hline & $1-4 \mathrm{Ni}$ & 5.76 & 0.65 & 1,705 & 9Ni steel & S5316 & 273 & none & none & none & 1,978 & $\$$ & 400 \\
\hline \multirow{8}{*}{ ॥ } & $11-2 A$ & 6 & 0.682 & 1,797 & S\$316 & none & 0 & S5316 wire & 0.212 & 622 & 2,420 & $\$$ & 700 \\
\hline & II-3A & 6 & 0.468 & 1,193 & SS316 & none & 0 & SS316 vire & 0.216 & 600 & 1,793 & $\$$ & 550 \\
\hline & II- $4 \mathrm{~A}-\mathrm{Mn}$ & 5.76 & 0.468 & 1,193 & High Mn steel & SS316 & 273 & SS316 wire & 0.216 & 600 & 2,066 & $\$$ & 550 \\
\hline & II-4A-Ni & 5.76 & 0.4 & 1,009 & 9Ni steel & SS316 & 273 & SS316 wire & 0.161 & 434 & 1,716 & $S$ & 450 \\
\hline & II-2B & 6 & 0.682 & 1,797 & SS316 & none & 0 & steel wire & 0.196 & 581 & 2,378 & $\$$ & 510 \\
\hline & II-3B & 6 & 0.468 & 1,193 & S\$316 & none & 0 & steel wire & 0.201 & 560 & 1,753 & $\$$ & 350 \\
\hline & II-4B-Mn & 5.76 & 0.468 & 1,193 & High Mn steel & 55316 & 273 & steel wire & 0.201 & 560 & 2,026 & $\$$ & 370 \\
\hline & II-4B-Ni & 5.76 & 0.4 & 1,009 & 9Ni steel & $\$ \$ 316$ & 273 & steel wire & 0.149 & 405 & 1,687 & $\$$ & 290 \\
\hline \multirow{2}{*}{ III } & III-AI & 6 & 0.236 & 193 & Aluminum & Al6061 & 0 & CF composite & $1.709^{*}$ & 1,180 & 1,373 & $\$$ & 1,760 \\
\hline & Ш-SS, 316 & 6 & 0.236 & 580 & Ss316 & \begin{tabular}{|l|l|}
55316 \\
\end{tabular} & 0 & C.F nommosite & $0.146^{*}$ & 262 & 843 & $\xi$ & 675 \\
\hline
\end{tabular}

* Wrapping material thickness was adjusted to meet the fatigue life requirement

\subsection{STATION DESIGN AND COST ANALYSIS}

\subsubsection{Overall Station Design}

Using the transient thermodynamic modeling tool, the thermal compression station was optimized for a $400 \mathrm{~kg}$ /day size refueling station. The model investigated multiple physical and operational variables of the thermal compression station in order to minimize capital cost and hydrogen boil off losses. The output of the model was the optimal number and volume of high pressure cryogenic hydrogen vessels (HPCHVs) required for the refueling station. Figure 16 is the process flow diagram (PFD) of the thermal compression fueling station showing the major equipment items and the required number of HPCHVs determined by the transient thermodynamic modeling.

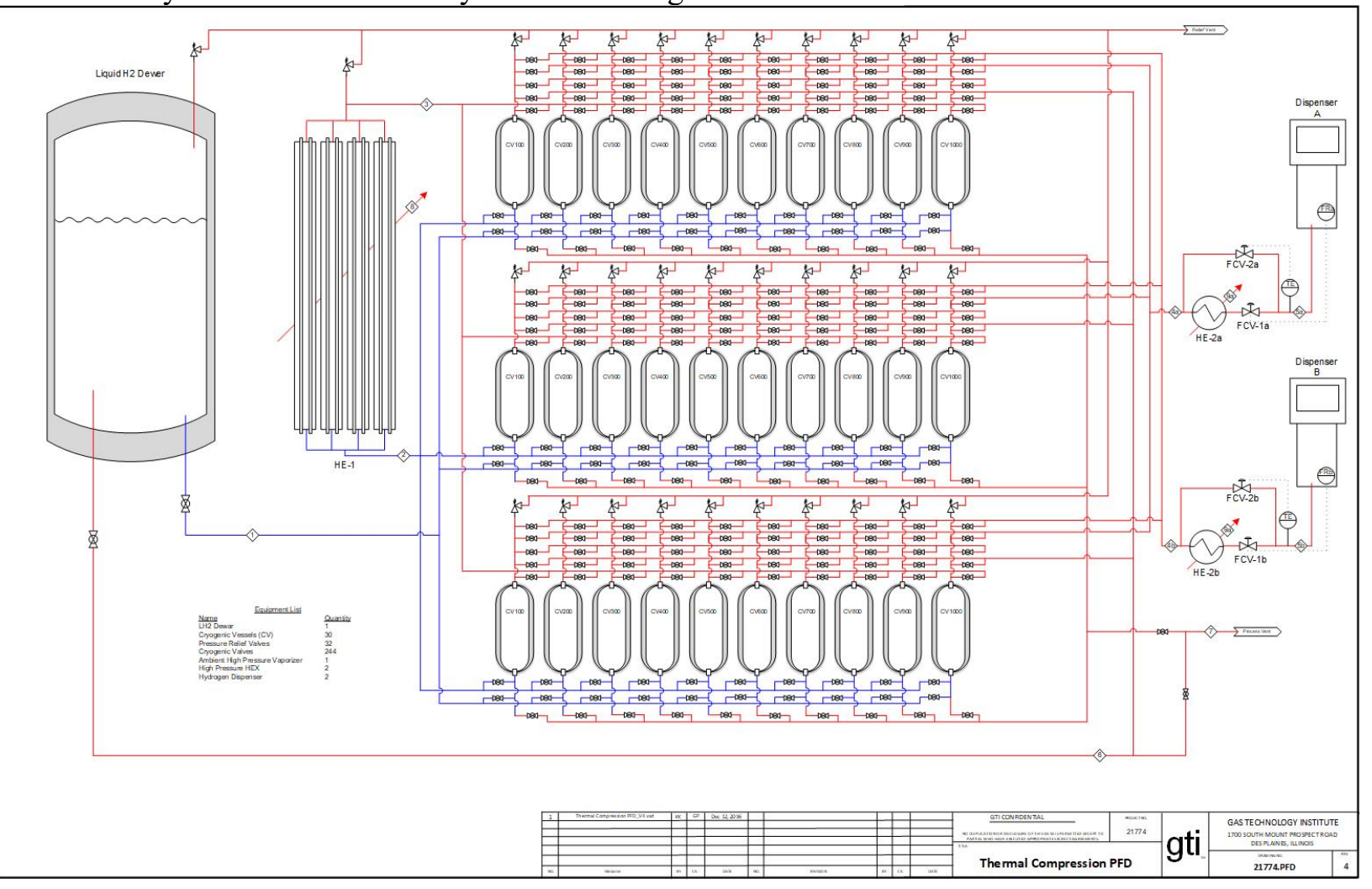


Figure 16. Process Flow Diagram for a $400 \mathrm{~kg} / \mathrm{day}$ Thermal Compressor Refueling Station

Figure 17 shows a 10 HPCHV section of the PFD. This figure identifies the process streams and includes a table listing the expected maximum and minimum process conditions for each stream. Stream 8 shows the amount of heat required to build the pressure in a HPCHV after it has been filled with LH2 and stream 9 a shows the amount of heat required to warm the hydrogen to the dispensing temperature.

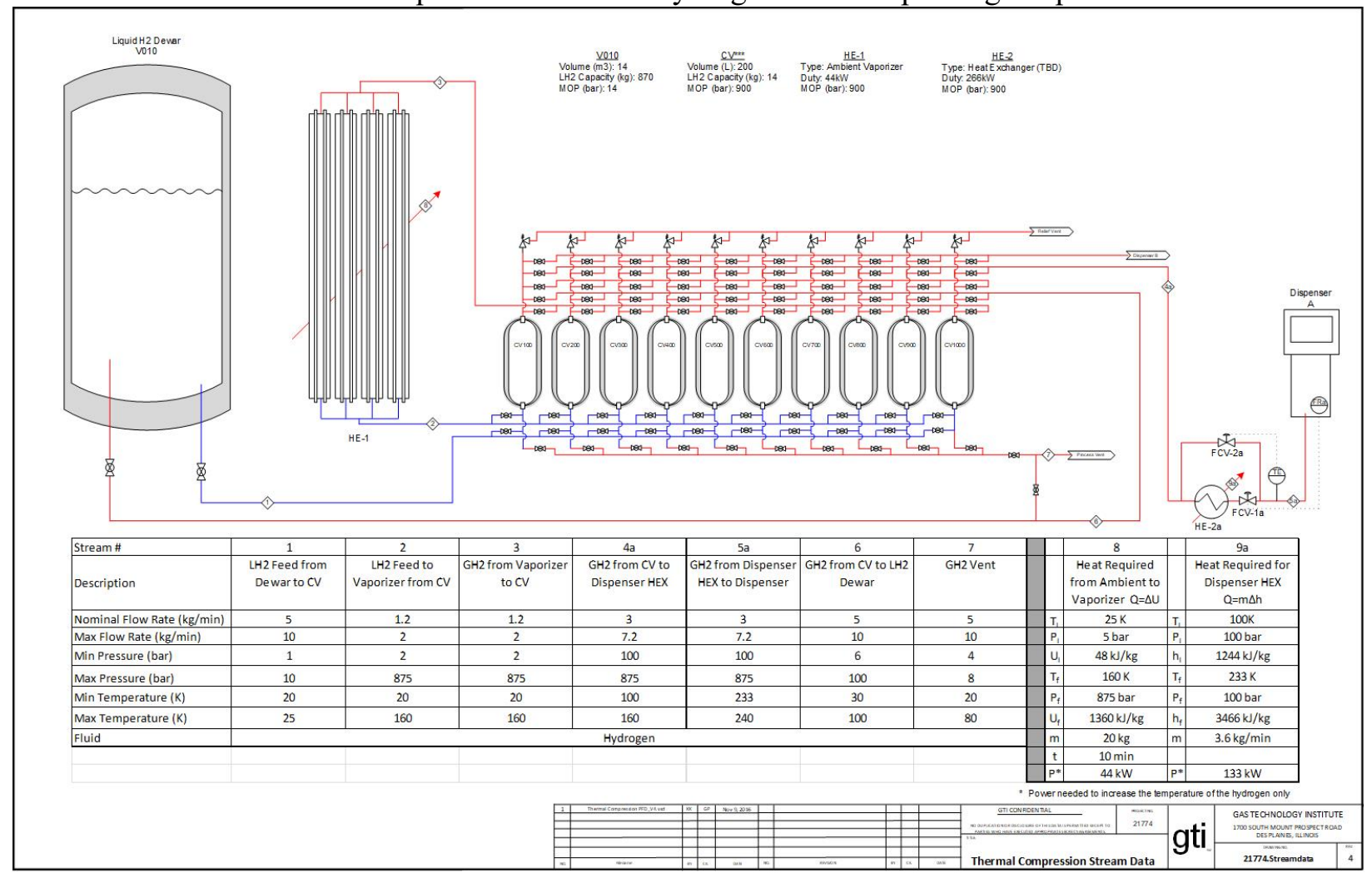

Figure 17. 10 HPCHV section of the thermal compression station PFD showing expected maximum and minimum process conditions.

The following section of the report will briefly describe the major equipment components of the thermal compressor station. These sections will emphasize the differences between the conventional and thermal compression station equipment and it will be pointed out how the equipment will be economically accounted for in the modified version of HDSAM.

\section{Liquid Hydrogen Storage Tank}

The liquid hydrogen storage tank stores the cryogenic hydrogen delivered to the station. The same size tank will be needed for both the thermal compression and the conventional refueling station. The thermal compression station will require access to a line to return hydrogen from the HPCHVs. As discussed in Figure 9, after thermodynamic evaluation it was determined that there were significant advantages to locating the return access port below the liquid level within the tank.

Because the size of the storage tank is the same for both the conventional and the thermal compression stations, no changes were made to this item in the thermal compression version of HDSAM.

\section{Pressure Building Heat Exchanger}

The pressure building heat exchanger, labeled HE-1 on Figure 16, is a high pressure ambient temperature vaporizer. This closed loop heat exchanger will be specifically designed to take liquid from the HPCHVs and warm it with heat from the surrounding ambient air allowing it to build pressure as it is returned to the source HPCHV. 
In HDSAM the cost of pressure building heat exchanger will be input into the cell that contains the cost of the evaporator heat exchanger found in a conventional station. Since the pressure building heat exchanger and the evaporator heat exchanger will be very similar in terms of footprint and installation, these cost factors were not adjusted from the conventional version of HDSAM.

The capital costs input for this heat exchanger used in the economic analysis stem from preliminary price quotes provided from high pressure vaporizor vendors.

\section{Dispenser Heat Exchanger}

In the traditional hydrogen refueling station, the hydrogen is cooled to $-40{ }^{\circ} \mathrm{C}$ before it is delivered to the dispenser. In the thermal compression station the hydrogen will need to be warmed to $-40^{\circ} \mathrm{C}$. This will be accomplished with ambient air heat exchangers similar to the pressure building vaporizer exchanger. These heat exchangers are labeled HE-2 $(\mathrm{a} \& \mathrm{~b})$ in Figure 16. The exchanger will be oversized to allow the hydrogen warm slightly above $-40^{\circ} \mathrm{C}$ and the temperature will be modulated using a stream of cold hydrogen which bypasses the dispenser heat exchanger. An exploded view of the heat exchanger bypass loop from the PFD is shown in Figure 18.

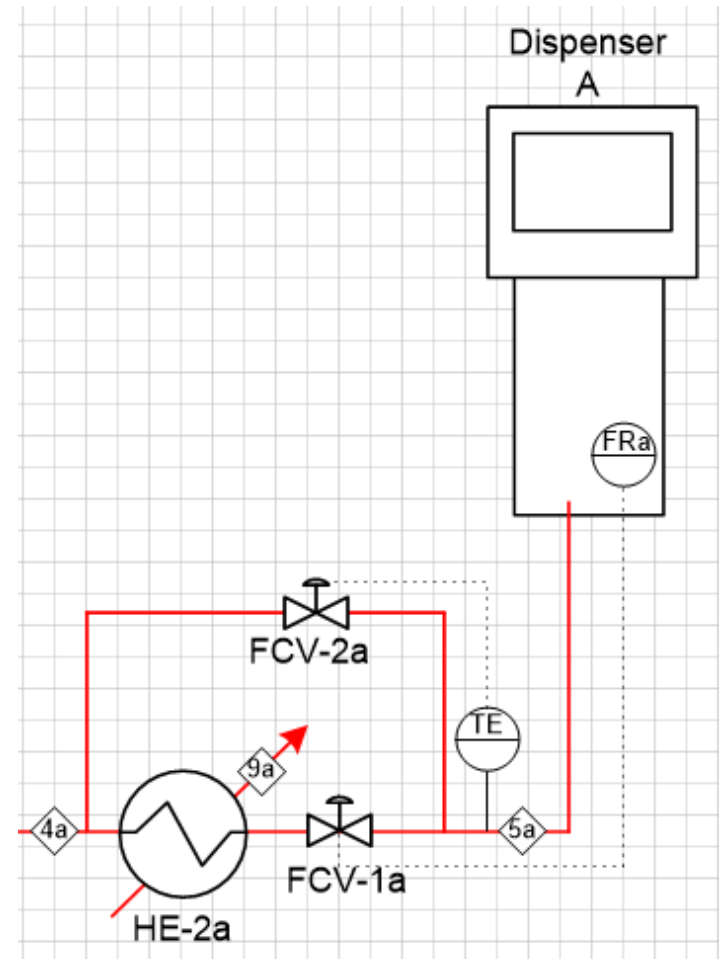

Figure 18. Dispenser Heat Exchanger and Bypass Loop

In the modified thermal compression version of HDSAM, the capital cost for the refrigeration unit(s) and the heat exchanger(s) of the conventional station were replaced with the cost of the heat exchangers. The electrical costs of operating the refrigeration chiller were also removed from the thermal compression version of HDSAM. The operating, maintenance, and installation costs of this heat exchanger were adjusted to reflect those of the evaporator due to the similarity of this equipment. Note that the cost of FCV-1a is accounted for in the "Overall Control and Safety" line item in HDSAM. Since both the conventional and the thermal compression station use this type of variable area dispenser controller, no adjustment was needed for this valve in the thermal compression version of HDSAM.

\section{Flow Control Valve}


Figure 18 shows the bypass flow control valve, labeled FCV-2a. The cost of this flow control valve has been added into the "Overall Control and Safety" item in the thermal compression version of HDSAM. This valve will need to be capable of operating at cryogenic temperatures as well as the 900 bar dispensing pressure. The amount of flow through this valve will be controlled by a temperature sensor downstream of the dispenser heat exchanger.

The capital cost of FCV-2a has been added to "Overall Control and Safety" line item in the thermal compression version of HDSAM. The cost of this valve used in the economic analysis was obtained via vendor quotation.

\section{Valves}

Thermodynamic modeling of the thermal compression process showed that hydrogen losses during the process could be minimized by incorporating pre-cooling and warming steps. In order to achieve these flow paths and meet the dispensing demands of a $400 \mathrm{~kg} /$ day station, each CPHCV will require eight high pressure cryogenic pneumatically actuated valves and one pressure relief valve. Figure 19 shows the open/close valve positions for snapshot in time during the operation of the thermal compression process. During full capacity 24 hour station operation each HPCHV will progress through the thermal compression cycle steps several times each day; therefore, each valve is needed to assure the step function can be completed independently of the state of operation of the other HPCHVs in the station.

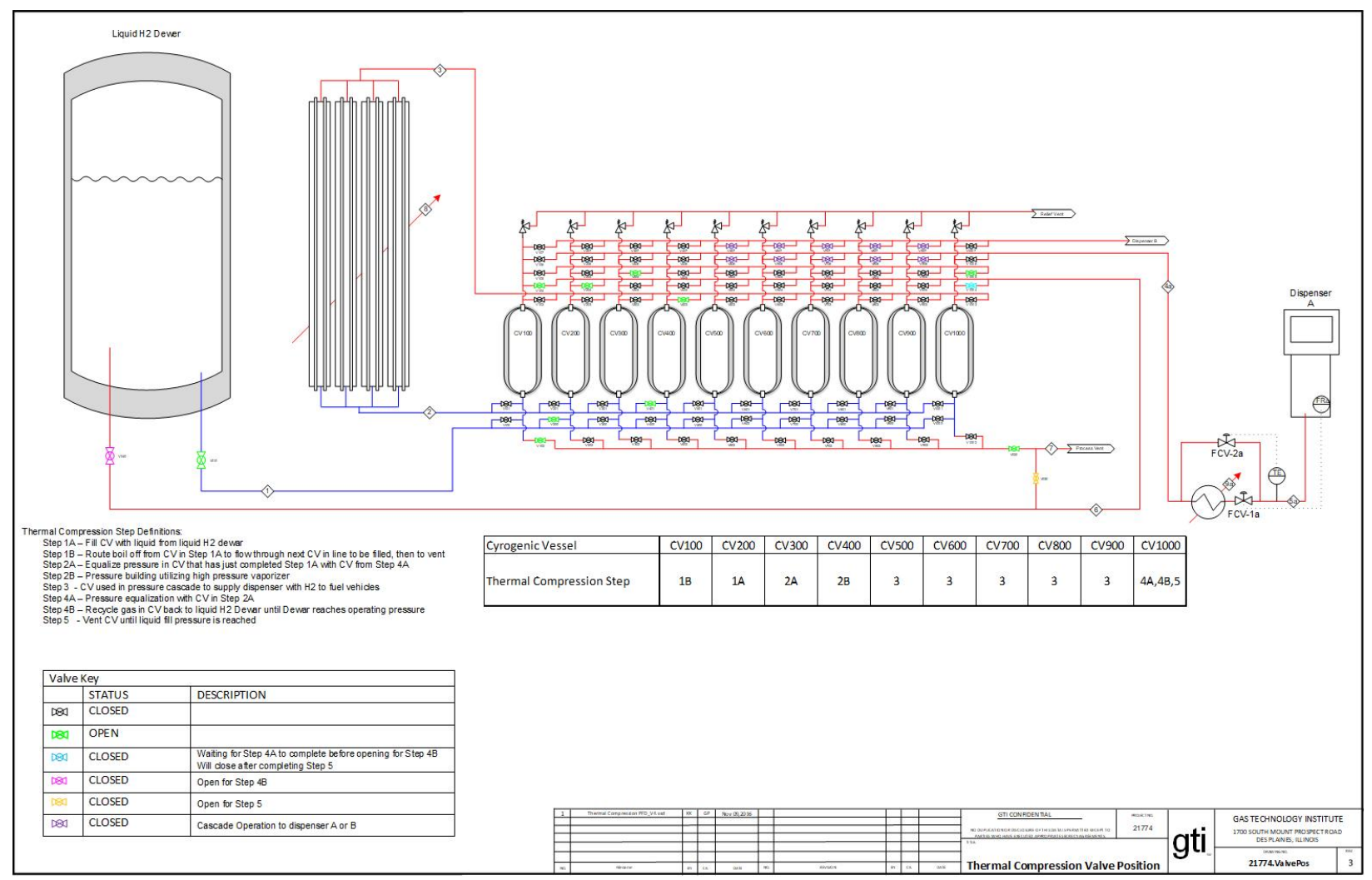

Figure 19. Valve Positions During the Thermal Compression Process

Because these valves will make up a considerable fraction of the overall station capital cost, an input row for the price of the valves was inserted into the modified thermal compression version of HDSAM.

The cost of each valve was varied as input to HDSAM in order to show the impact on the overall capital costs. The quantity of valves needed in the thermal compression design should make this equipment eligible for production volume discounts; however, the level of discount is difficult to determine so this cost will be presented at different cost values. 
The increased complexity in the installation of all the valves and associated fittings is accounted for in HDSAM by increasing the valve installation factor from 1.0 to 1.1 .

\section{Dispenser}

A $400 \mathrm{~kg} /$ day size station capable of keeping up the demand profile will require the ability for two vehicles to fuel simultaneously. The costs of dispensers are assumed to be the same for both the conventional and thermal compressor versions of HDSAM.

\section{Balance of Plant (BOP)}

The BOP equipment consists of items such as controls, safeties, piping, and electrical. While the safety and control strategies may be similar between the conventional and the thermal compression stations, the quantity of valves utilized in the thermal compression station will increase the number of balance of plant items. These items include pressure relief devices and the interconnecting fittings and tubing needed to create the manifolds for each vessel as well as the bypass flow control valve for the dispenser. This difference in cost is addressed in HDSAM by increasing the balance of plant contribution from $\$ 100,000$ in the conventional case to $\$ 190,000$ in the thermal compression case.

\section{HPCHVs}

The cost of the HPCHVs options were defined in Table 6 for a $200 \mathrm{~L}$ inner volume, 6 inch. Inner diameter, 900 bar rated pressure vessel design. Those costs were expressed as function of the inner volume in order to optimize the station costs as a function of the size and number of HPCHVs in the cascade. Figure 20 shows the influence of volume on the pressure vessel cost for a few selected designs from Table 6. The cost of Multi-Layer Vacuum Insulation, including the vacuum jacket, is also included, based on extrapolations from [12].

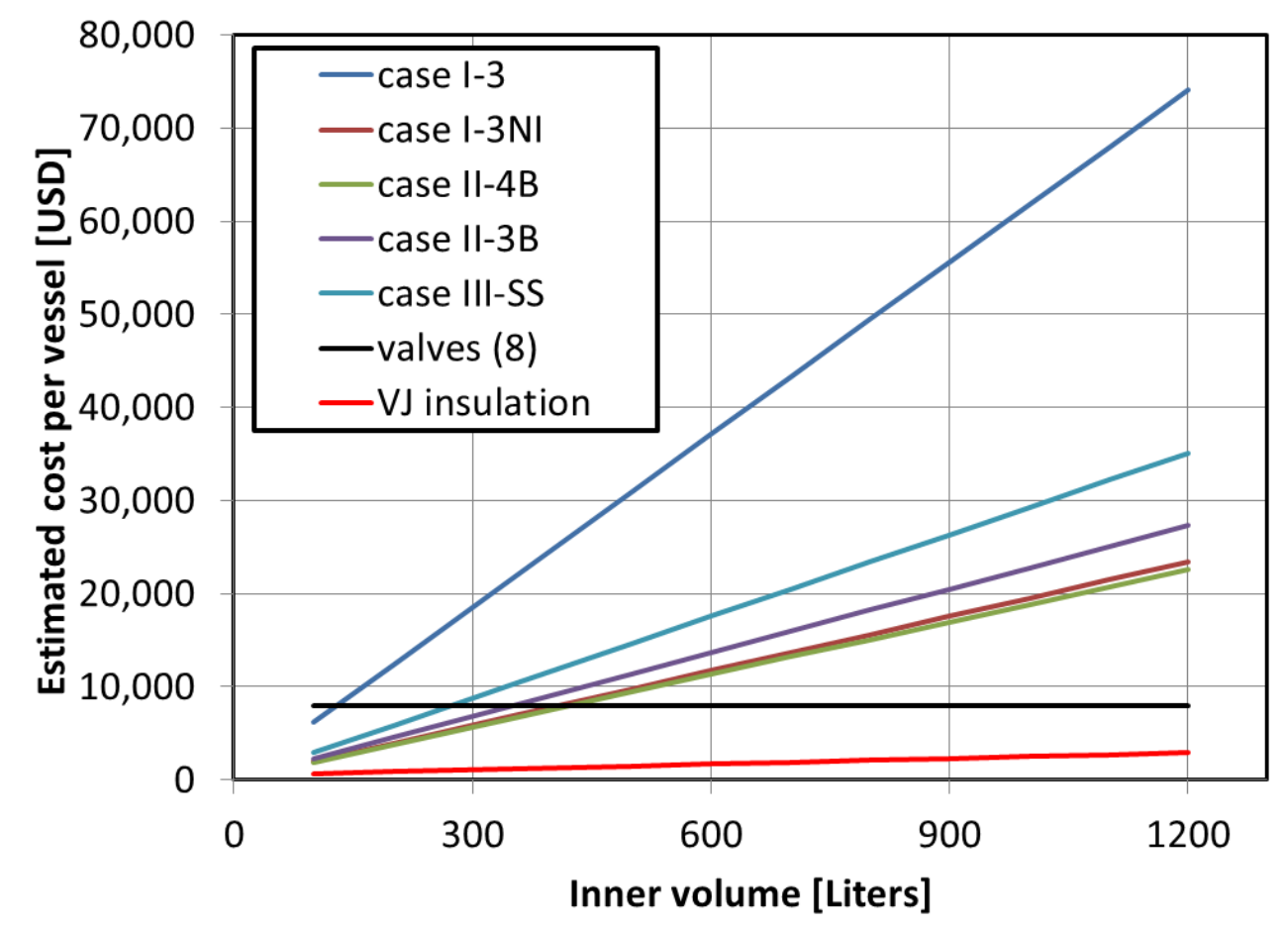

Figure 20. Cost of pressure vessels as function of the inner volume (6 in. inner diameter, 900 bar rated pressure). The vaccum jacket cost using MLVS is also included. 
production level case is $\$ 11.21 / \mathrm{kg}$ and $\$ 9.09 / \mathrm{kg}$ for the mid-level production case. The $15 \%$ reduction of these costs for the go-no/go criteria would be $\$ 9.53 / \mathrm{kg}$ for the low production volume case and $\$ 7.73 / \mathrm{kg}$ for the mid-level production case.

Table 7. Capital Cost Breakdown for Convention Hydrogen Refueling Station

\begin{tabular}{|c|c|c|c|c|c|c|}
\hline \multicolumn{7}{|c|}{ Conventional Station } \\
\hline \multirow[b]{2}{*}{ Equipment } & \multirow[b]{2}{*}{ Quantity } & \multirow[b]{2}{*}{$\begin{array}{l}\text { Installation } \\
\text { Cost Factor }\end{array}$} & \multicolumn{2}{|c|}{ Low Production Level } & \multicolumn{2}{|c|}{ Mid Production Level } \\
\hline & & & $\begin{array}{c}\text { Uninstalled } \\
\text { Cost }\end{array}$ & $\begin{array}{c}\text { Installed } \\
\text { Cost }\end{array}$ & $\begin{array}{c}\text { Uninstalled } \\
\text { Cost }\end{array}$ & $\begin{array}{c}\text { Installed } \\
\text { Cost }\end{array}$ \\
\hline Refrigeration & & & & $\$ \quad 209,615$ & & $\$ \quad 144,435$ \\
\hline Chiller & 1 & 2.4 & 37,365 & & 29,445 & \\
\hline Heat Exchanger & 2 & 2.3 & 51,564 & & 31,612 & \\
\hline LH2 Storage Tank & $1608 \mathrm{~kg}$ & 1.3 & 17,402 & 221,522 & 134,285 & 174,570 \\
\hline Dispensers & 2 & 1.3 & 200,000 & 260,000 & 94,034 & 122,244 \\
\hline Electrical & $480 \mathrm{~V}$ & 2.24 & 36,880 & 82,612 & 38,595 & 86,453 \\
\hline Cascade & & 1.3 & 373,172 & $\$ \quad 485,124$ & 152,521 & 198,278 \\
\hline Inner vol ume (L) & & & 4,370 & & 2,913 & \\
\hline Evaporator & 1 & 1.3 & 39,761 & 51,690 & 35,533 & 46,193 \\
\hline Gas Compressor & 1 & 1.3 & 712,075 & $\$ \quad 925,697$ & 376,199 & 489,058 \\
\hline $\mathrm{kW}$ & & & 96 & & 117 & \\
\hline BOP & & 1 & 100,000 & $\$ 100,000$ & 100,000 & 100,000 \\
\hline Total & & & $1,568,219$ & $\$ 2,336,260$ & 992,224 & $\$ 1,361,231$ \\
\hline Delivered H2 Cost & & & & $\$ 11.21 / \mathrm{kg}$ & & $\$ 9.09 / \mathrm{kg}$ \\
\hline $15 \%$ Target & & & & $\$ 9.53 / \mathrm{kg}$ & & $\$ 7.73 / \mathrm{kg}$ \\
\hline
\end{tabular}

Table 8. Summary of levelized cost break down for conventional fueling station case

\begin{tabular}{|c|c|c|c|c|c|c|c|c|c|c|}
\hline \multicolumn{11}{|l|}{ Cost Breakdown } \\
\hline \multirow[b]{2}{*}{ Total Cost [\$/kg] } & \multicolumn{2}{|c|}{ Liquefier [ $\$ / k g]$} & \multicolumn{2}{|c|}{ Terminal [\$ikg] } & \multicolumn{2}{|c|}{$\begin{array}{l}\text { Tractor-Trailer } \\
\text { [\$/kg] }\end{array}$} & \multicolumn{2}{|c|}{$\begin{array}{l}\text { Liquid Refueling } \\
\text { Station [\$/kg] }\end{array}$} & \multicolumn{2}{|c|}{ Sum [\$ikg] } \\
\hline & $\$$ & 4.05 & $\$$ & 0.60 & $\$$ & 0.26 & $\$$ & 4.17 & $\$$ & 9.09 \\
\hline Capital & $\$$ & 2.46 & $\$$ & 0.35 & $\$$ & 0.14 & $\$$ & 2.16 & $\$$ & 5.12 \\
\hline Other OtM & $\$$ & 0.68 & $\$$ & 0.25 & $\$$ & 0.09 & $\$$ & 1.50 & $\$$ & 2.53 \\
\hline Energy/Fuel & $\$$ & 0.91 & $\$$ & 0.00 & $\$$ & 0.02 & $\$$ & 0.51 & $\$$ & 1.44 \\
\hline
\end{tabular}

\section{Thermal Compression Version of HDSAM}

A specific version of HDSAM was created to model the economics of a thermal compression station. This version of HDSAM accounted for the differences in capital equipment as well as operating and maintenance costs associated with the thermal compression station. Other factors that contributed to the overall levelized cost calculation of the delivered hydrogen were not modified. These factors include costs occurring at the liquefier, terminal, and tractor-trailer. Efforts were made to keep the modifications made to HDSAM as minimal as possible so that it would be an accurate comparison tool between the conventional and thermal compression stations. HDSAM programmers at Argonne National Lab were consulted concerning the changes that were made in order to confirm that all of the economic impacts of 
the changes were realized in the final levelized cost values. The input data and the results for the thermal compression station are discussed in the following section.

\subsubsection{Results}

The thermodynamic modelling was used to optimize the station design in terms of capital cost and operational costs. The HPCHV research provided a list of potential vessel designs suitable for the thermal compression cycle. The station design generated a list of equipment that needed to be accounted for in the economic analysis of the thermal compression station. The results of the project can be viewed from the standpoint of capital cost and operational costs.

\section{Capital Costs}

Table 9 shows the equipment that can be eliminated from the conventional fueling station when performing the economic evaluation of the thermal compression station. Note that in addition to some major equipment items a large capital electric cost can also be removed. The lack of electrical needs in the thermal compression station will also be noticed in the termal compression station's operating cost.

Table 9. Equipment eliminated from conventional hydrogen fueling stations

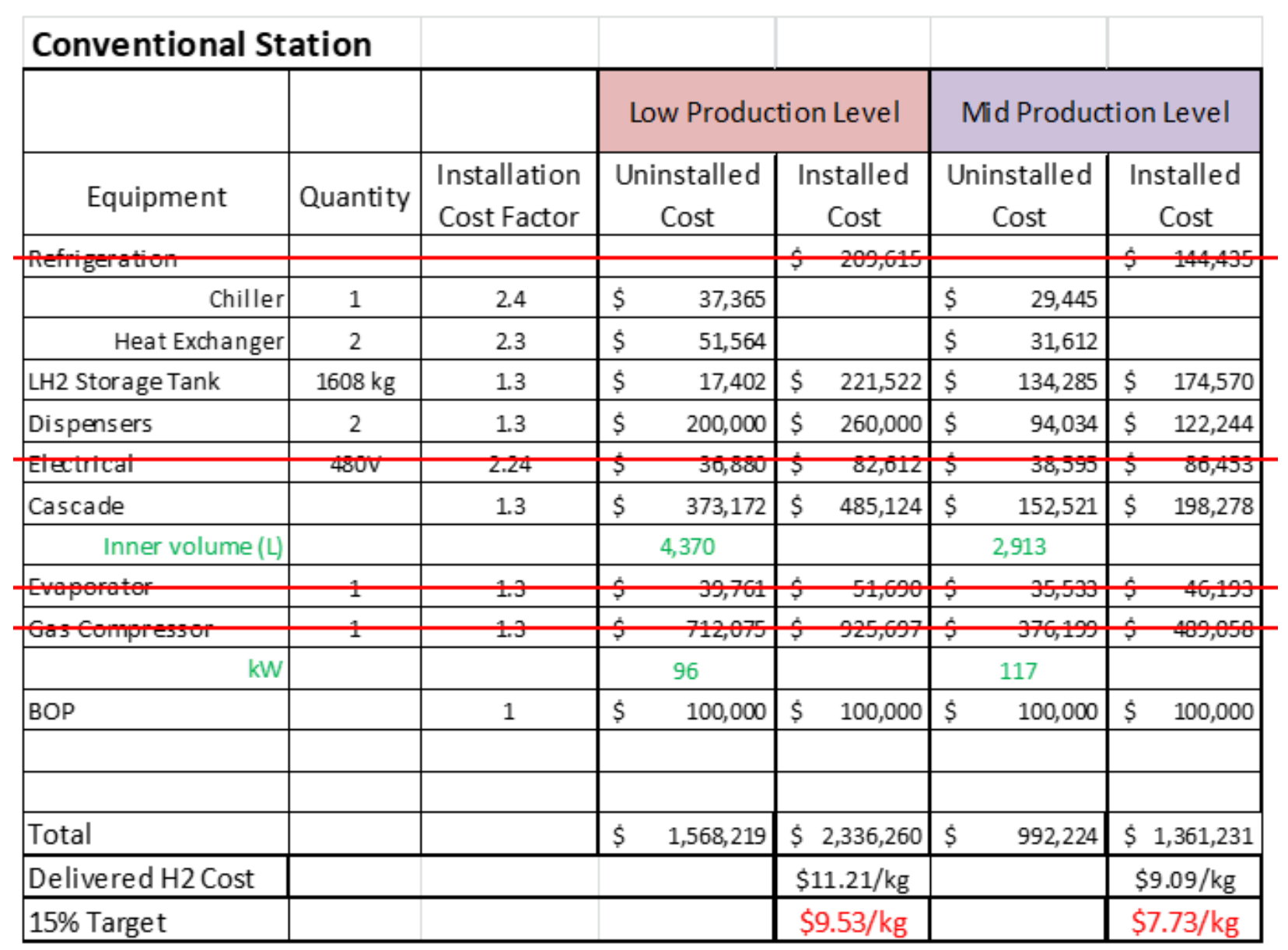

Table 10 lists the capital cost input values for the thermal compression station. These values were entered into the customized version of HDSAM. Equipment highlighted in blue point out items specific to the thermal compression station. The cost of the vessels in the cascade is assumed to be $\$ 290 / \mathrm{kgH} 2$ (type II- 
4B-Ni of Table 6). The low production level values are for $16 \mathrm{HPCHVs}$ with an internal volume of $600 \mathrm{~L}$ and a valve cost of $\$ 1000$ per valve. The mid production case represent cost values for 29 HPCHVs with an internal volume of $200 \mathrm{~L}$ and valves at $\$ 700$ per valve.

Table 10. Capital cost input for thermal compression station

\section{Compressor- \\ less Station}

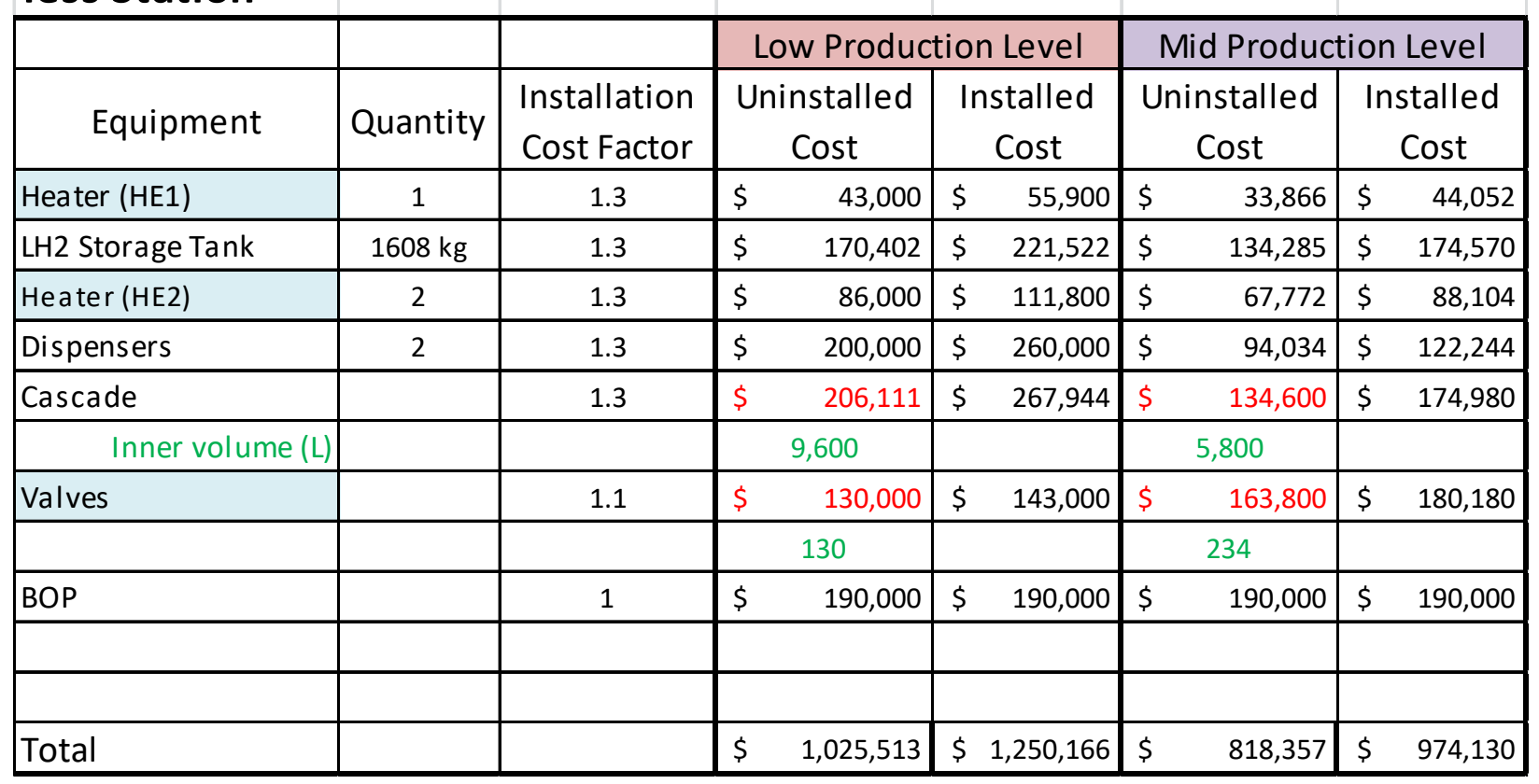

Table 11 shows the thermal compression station does have a capital cost advantage over the conventional refueling station. However, this advantage margin is much less for the mid production case. The main factor for the narrowing of this gap is the cost reduction potential realized by the hydrogen compressor when production level increases.

Table 11. Capital cost comparison between convention and thermal compression stations

\begin{tabular}{|l|l|l|}
\hline & Low Production Level & Mid Production Level \\
\hline Conventional & $\begin{array}{l}\mathbf{\$ 2 . 3} \mathbf{M} \\
\left(4.4 \mathrm{~m}^{3} \text { cascade + compressors }\right)\end{array}$ & $\begin{array}{l}\mathbf{\$ 1 . 3} \mathbf{M} \\
\left(2.9 \mathrm{~m}^{3} \text { cascade + compressors }\right)\end{array}$ \\
\hline Compressor-less & $\mathbf{\$ 1 . 2 5} \mathbf{M}$ & $\mathbf{\$ 1} \mathbf{M}$ \\
& $\left(\mathbf{9 . 6 \mathrm { m } ^ { 3 } \text { insulated cascade } )}\right.$ & $\left(5.8 \mathrm{~m}^{3}\right.$ insulated cascade $)$ \\
\hline
\end{tabular}

\section{Operational Costs}

The thermal compression station does have some advantages over the conventional station in operating costs. Factors for electrical consumption, maintenance parts, and labor were able to be reduced or eliminated in the thermal compression version of HDSAM. However, one major operational parameter, 
the amount of hydrogen boil-off, far outweighed any operational advantages gained by the thermal compression station.

Figure 22 shows the variations of Dewar vapor pressure and boil-off losses as the thermal-compression hydrogen refueling station is used, starting from a Dewar initially full (1608 kg LH2 at $20 \mathrm{psia})$. As H2 is delivered to the vehicles, the Dewar vapor pressure increases up to near 90 psia then decreases. At the same time, more and more boil-off losses occur, mainly due to the cooling of the pressure vessels in the cascade. The boil-off losses culminated here are at $600 \mathrm{~kg} \mathrm{H} 2$ for $1000 \mathrm{~kg} \mathrm{H} 2$ dispensed to the vehicles. Assuming a $400 \mathrm{~kg} \mathrm{H} 2 /$ day, about $250 \mathrm{~kg} \mathrm{H} 2$ are lost every day. Figure 23 shows different results using a Type II-4B-Ni HPCHV design, with or without recovery, and including levelized costs calculated from HDSAM.

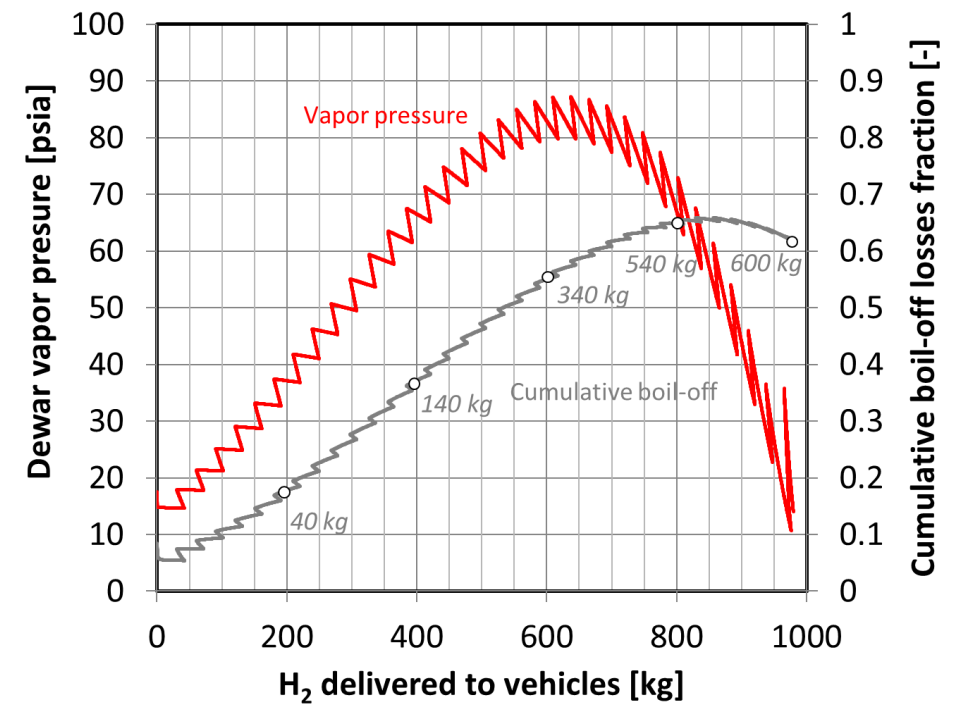

Figure 22. Dewar pressure and boil-off variations as a function of the amount of $\mathrm{H2}$ delivered to the vehicle, for a thermalcompression refueling station, using steel lined type III vessels and recovery methods. The Dewar is $22.7 \mathrm{~m} 3$ and initially hold $1608 \mathrm{~kg}$ of LH2 at 20 psia.

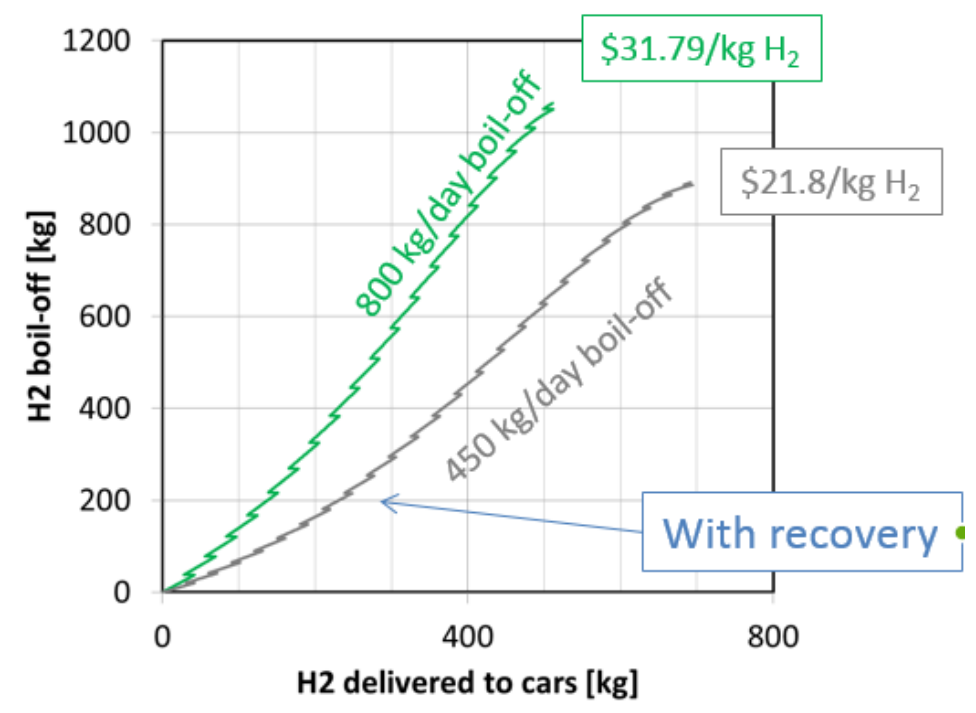


Figure 23: Boil-off during operation of a station using a thermal-compression concept, for a Type II-4B-Ni pressure vessel design, assuming mid production levels.

These large boil-off losses are obviously impractical for a fueling station design. Too much boil-off occurs due to the need to remove the heat from the wall of the pressure vessels before being able to fill the vessels again with LH2. Methods to reduce the effects of thermal mass exist, such as vapor cooled shielding liner [22]. Assuming that such a solution could be effectively implemented, reducing the cooling needs to virtually zero, the boil-off would be reduced from $450 \mathrm{~kg} \mathrm{H} 2 /$ day to $63 \mathrm{~kg} \mathrm{H} 2 /$ day. This $63 \mathrm{~kg} /$ day quantity can be attributed to the transfer losses ("PdV" work). In order to reduce those losses even further, a small throughput compressor and a fuel cell could be added to the design. Some of the boil-off $\mathrm{H} 2$ would be utilized in the fuel cell that would then power a compressor. The compresor would harvest the remaining low pressure hydrogen earmarked for boil-off and compress it into a HPCHV already active in the cascade fueling operation.

It is recognized that this fuel cell/compressor addition is contrary to one of the initial goals of the project, which was to eliminate the maintenance and operational complexity compressors bring to hydrogen fueling stations. However, this scenario was briefly investigated in order to evaluate at least one possible solution for mitigating the hydrogen boil-off losses. Assuming mid production volumes, a $300 \mathrm{bar} 20 \mathrm{~kW}$ compressor and a fuel cell would cost around $\$ 90 \mathrm{k}$. Including extra O\&M, it is thus estimated that a "boil-off free" thermal compression hydrogen refueling station (some of the boil-off would be used to power a fuel cell + compressor system, that would capture the remaining boil-off) using type II-4B-Ni pressure vessel would enable a mid production levelized cost of $\$ 8.55 / \mathrm{kg} \mathrm{H} 2$. It is important to note here that such a system relies on the assumption that the pressure vessel are thermal-mass free, a concept that has never been demonstrated thus far.

\section{SUBJECT INVENTIONS}

No inventions were filed under this CRADA.

\section{COMMERCIALIZATION POSSIBILITIES}

The insights and knowledge gained from this work under the CRADA provides a baseline feasibility evaluation of the thermal compression station. Although the current technology evaluated for a thermal compression station could not reach a reduction in the cost of delivered hydrogen by the target $15 \%$ when compared to a conventional station, the areas for future research development and improvement are identified.

\section{PLANS FOR FUTURE COLLABORATION}

ORNL plans to continue to seek future collaboration opportunities with LLNL, Shell and GTI on thermal compression hydrogen fueling station design and optimization.

\section{CONCLUSIONS}

This study set out to investigate the technical and economical feasibility of using thermal compression to provide the pressure necessary in hydrogen refueling stations. To accomplish this investigation two transient thermodynamic model were created. The models fed information necessary to complete other 
tasks necessary to complete the feasibility study, namely, the HPCHV design and the overall station design.

The thermodynamic modeling provided temperature, pressure, and quantity of cycle boundaries for research into the availability of cyrogenic storage vessels necessary for this process. A literature search revealed that there were no existing vessel designs "on the shelf" for this thermal compression process. The vessel study resulted in several potential candidate vessels, but it was recognized that these vessels would require rigorous validation testing before they would be allowed to be deployed in hydrogen fueling stations. It was positive to note that over the course of the vessel research, ORNL's industrial collaborators and vendors did provide enthusiastic feedback and in one case even offered to provide costshare for future research into these types of cryogenic vessels.

The thermodynamic modeling also fed necessary input into the overall station design so station CAPEX and OPEX could be estimated. Initial model results indicated hydrogen boil-off was going to be a major concern for this type of station. Flow strategies were implemented in the station design for the purpose of minimizing hydrogen losses. These strategies altered the original conceptual designs of the station making the number of high pressure cryogenic valves much larger than expected. The large number of valves not only made the station operation more complicated and reliant on valve performance, the cost of the valves minimized the capital cost advantage the thermal compression station had over conventional stations.

Unfortunately even after the hydrogen boil off strategies were programmed into the model, the simulations showed the thermal compression process still resulted in a significant amount of hydrogen not being delivered to the vehicle. Even with the HPCHV with the lowest thermal mass, cooling the HPCHV from $160 \mathrm{~K}$ to $20 \mathrm{~K}$ during Step 1 of the process resulted in too much unusable low pressure hydrogen. HDSAM showed that, when the boil-off losses were included, the station and the HPCHVs presented in this study could not lower the cost of delivered hydrogen below that of existing conventional stations.

In order to complete the feasibility study, an optimistic thermal compression station was evaluated. This design utilized HPCHVs that required minimal vessel wall cooling in step 1 of the process. The station also used a compressor to harvest any residual low pressure hydrogen stranded by the process and powered that compressor using a fuel cell fed by the stranded low pressure hydrogen. Even with the use of this theoretical vessel and optimistic CAPEX and OPEX values inserted into HDSAM for the compressor/fuel cell station design, the thermal compression station could only reduce the cost of delivered hydrogen by $6 \%$ when compared to a conventional station.

Components of the thermal compression station, specifically, the HPCHVs, heat exchangers, hydrogen storage Dewars, and flow controlling cryogenic dispensing valves, still require significant research and development efforts. HDSAM is also predicting that costs of compressors and liquid hydrogen pumps have the potential to significantly decrease as production level and experience with this equipment increases. If this happens, this will further reduce any advantage thermal compression has over conventional stations. Given the fact that the project did not achieve its goal of a $15 \%$ reduction in delivered hydrogen costs and so much research and development was still needed to achieve the most optimistic thermal compression station design, DOE decided to issue this project a no-go.

\section{REFERENCES}

[1] [Online]. Available: https://www.hydrogen.energy.gov/h2a_delivery.html.

[2] T.-P. Chen, "Hydrogen Delivery Infrastructure Options Analysis," Nexant, 2008. [Online]. Available: https://energy.gov/sites/prod/files/2014/03/f11/delivery_infrastructure_analysis.pdf. 
[3] S. M. A. N. G. Guillaume Petitpas, "Vehicle Refueling with Liquid Hydrogen Thermal Compression," Vols. 37, 11448-11457, April 2012.

[4] M. L. H. a. M. O. M. E. W. Lemmon, "“NIST Standard Reference Database 23: Reference Fluid Thermodynamic and Transport Properties-REFPROP."," National Institute of Standards and Technology, Standard Reference Data Program, Gaithersburg, 2007.

[5] M. M. B. K. M. H. a. M. P. A. Elgowainy, "Optimization of Compression and Storage Requirements at Hydrogen Refueling Stations," in ASME Conf. Proc., vol. 2008, no. 48289, pp. 131-136, Jan. 2008.

[6] M. M. a. D. B. A. Elgowainy, "Refueling Station Cost Analysis Using HDSAM," in DTT Meeting USCAR, Southfield MI, March 16, 2011.

[7] A. E. a. E. S. K. Reddi, "Hydrogen refueling station compression and storage optimization with tubetrailer deliveries," International Journal of Hydrogen Energy, vol. 39, no. 33, p. 19169-19181, Nov. 2014.

[8] "SAE TIR J2601- Fueling Protocols for Light Duty Gaseous Hydrogen Surface Vehicles," 16 March 2010. [Online]. Available: www.sae.org.

[9] M. F. a. V. S. M. Daigle, "Model-based diagnostics for propellant loading systems 2011," in Aerospace Conference pp. 1-11, 2011.

[10] Z. Z. W. W. J.-A. a. R. F. Feng, "Manufacturing Cost Analysis of Novel Steel/Concrete Composite Vessel for Stationary Storage of High-Pressure Hydrogen," Technical Report ORNL/TM2013/113. DOI: 10.2172/1072154, 2013.

[11] J. Burtscher, "CRYO-COMPRESSED HYDROGEN (CCH2) - ROADMAP FROM VALIDATION TO REGULATION," ICHS-2013.

[12] R. H. T. a. P. J. Ahluwalia, "Technical Assessment: Cryo-Compressed Hydrogen Storage for Vehicular Applications," Internaional Journal of Hydrogen Energy, vol. 35, no. 9, Pages 4171-4184, 2010.

[13] e. a. O. Kircher, in BMW Group,Int. Conf. on Hydrogen safety, San Francisco, CA, 2011.

[14] S. M. A. F. E.-L. e. A.H Weisberg, Interntaional Journal of Hydrogen Energy, vol. 38, pp. 9271-9284, 2013.

[15] K. Simmons, "Projected for projected for mass production," [Online]. Available: https://www.hydrogen.energy.gov/pdfs/review13/st101_simmons_2013_o.pdf.

[16] 2015 ASME Boiler \& Pressure Vessel Code, ASME BVP Sec VIII, Div.2. .

[17] c. W. Communication with US vendor.

[18] Z. L. e. a. C. Zhou, International Journal of Hydrogen Energy, vol. 39, p. 13634, 2014.

[19] Z. F. e. Y. Wang, "Cost analysis of hydrogen storage vessel at 875 bar," ORNL Technical report, ORNL/TM-2016/94; Oak Ridge National Laboratory, March 2016.

[20] Communication with US vendor, company $W$.

[21] Communication with US vendor, company $H$.

[22] J. L. a. P. Adam, "Vapor Cooled Shielding Liner for Cryogenic Storage in Composite Pressure Vessels," 12-Feb-2016. 